\title{
Renal dysfunction in liver transplantation: The problem and preventive strategies
}

\author{
Marcelo Cantarovich MD
}

M Cantarovich. Renal dysfunction in liver transplantation: The problem and preventive strategies. Can J Gastroenterol 2004;18(Suppl C):27C-40C.

Ongoing improvements in survival following liver transplantation have necessitated a re-evaluation of immunosuppression protocols. Corticosteroids and calcineurin inhibitors (CNIs) are the most frequently used immunosuppressive drugs for liver transplantation but are associated with a wide range of adverse effects, such as hypertension, hyperlipidemia and nephrotoxicity. The need for hemodialysis after liver transplantation is associated with poor outcomes. Renal dysfunction in this setting may be caused by pre-existing renal disease, hepatorenal syndrome and/or post-transplant factors, including the use of nephrotoxic drugs, most notably CNIs such as cyclosporine and tacrolimus. The methods that address this problem include the diligent control of metabolic factors (eg, hypertension and hyperlipidemia), therapeutic monitoring of CNIs and withdrawal or reduction of the dosage of CNIs, combined with the use of newer non-nephrotoxic agents. Although there is no clear consensus about the most effective strategy, the optimal long-term immunosuppressive regimen would prevent rejection without causing nephrotoxicity or other significant adverse effects. Recent evidence suggests that the liver is a tolerogenic organ and that some patients may need little, if any, long-term immunosuppression.

Key Words: Calcineurin inhibitors; Corticosteroids; Cyclosporine; Immunosuppression; Liver transplantation; Renal dysfunction; Tacrolimus

T iver transplantation (LT) has become a viable therapeutic Lintervention for nearly all individuals with end-stage liver disease, but there has been increasing attention to the issues of long-term morbidity and mortality (1-3). Chronic immunosuppression probably accounts for most morbidity, and malignancy and infection remain major causes of mortality (4). Renal dysfunction can also be attributed, in part, to the adverse effects of chronic immunosuppressives (3). The nephrotoxic effects of the calcineurin inhibitors (CNIs), cyclosporin A (CsA) and tacrolimus, have been extensively reviewed (5-7). Progressive loss of renal function has been documented in the native kidneys of heart, lung and bone marrow recipients undergoing long-term immunosuppression with CsA (8-11). CNI-associated nephrotoxicity leads to acute renal failure (ARF) in $17 \%$ to $38 \%$ of cases $(12,13)$. Chronic renal failure or end-stage renal disease (ESRD) may also occur in up to $18 \%$ of LT recipients surviving 13 years or longer (14).

\section{La dysfonction rénale dans la greffe du foie : Le problème et les stratégies préventives}

\begin{abstract}
Les améliorations constantes aux taux de survie après une greffe du foie ont exigé une réévaluation des protocoles d'immunosuppression. Les corticoïdes et les inhibiteurs de la calcineurine (ICN) sont les immunosuppresseurs les plus utilisés pour les greffes du foie, mais ils s'associent à une vaste gamme de réactions néfastes, telles que l'hypertension, l'hyperlipidémie et la néphrotoxicité. Le besoin d'hémodialyse après une greffe du foie est relié à des issues négatives. Une dysfonction rénale peut être causée par la maladie rénale préexistante, un syndrome hépatorénal ou des facteurs post-greffes, y compris le recours à des médicaments néphrotoxiques, notamment des ICN tels la cyclosporine et le tacrolimus. Les méthodes utilisées pour étudier ce problème sont le contrôle diligent des facteurs métaboliques (p. ex., hypertension et hyperlipidémie), la surveillance thérapeutique des ICN et le retrait ou la réduction de la posologie des ICN, associé à l'utilisation des agents non néphrotoxiques les plus récents. Bien qu'il n'existe pas de consensus clair quant à la stratégie la plus efficace, la posologie immunosuppressive optimale à long terme préviendrait le rejet sans causer de néphrotoxicité ou d'autres réactions négatives marquées. Les données probantes récentes indiquent que le foie est un organe tolérogène et que certains patients ont peut-être besoin d'une immunosuppression minimale à long terme, ou même d'aucune immunosuppression.
\end{abstract}

Department of Medicine, Division of Transplantation, Multi-Organ Transplant Program, Royal Victoria Hospital, McGill University Health Centre, Montreal, Quebec

Correspondence: Dr Marcelo Cantarovich, Royal Victoria Hospital, McGill University Health Centre, Department of Medicine, Multi-Organ Transplant Program, 687 Pine Avenue West, Ross 2.58, Montreal, Quebec H3A 1A1. Telephone 514-842-1231 ext 34969,

fax 514-843-1708, e-mail marcelo.cantarovich@muhc.mcgill.ca 
efforts have been aimed at reducing the incidence of renal dysfunction and other adverse events. Some studies have suggested that the majority of LT patients are over-immunosuppressed $(16,17)$, and that the liver might be a tolerogenic organ (18). The optimal immunosuppressive regimen has not been firmly established, and trials of CNI therapeutic drug monitoring, reduced $\mathrm{CNI}$ dosing, $\mathrm{CNI}$ withdrawal and $\mathrm{CNI}$ avoidance following LT are ongoing. The present review focuses on the problem of renal dysfunction in LT recipients, contributing factors and strategies to reduce its incidence and long-term consequences.

\section{FACTORS AFFECTING POST-LT RENAL FUNCTION}

Several patient-related variables, both before and after LT, can affect renal function after surgery (19). Therefore, efforts have been made to preoperatively identify patients who would be most likely to benefit from a renal-sparing immunosuppressive regimen and for whom combined liver-kidney transplantation might be needed.

\section{Renal diseases associated with hepatic failure}

Several glomerular diseases, which can be difficult to diagnose in patients undergoing LT, occur with liver disease. In patients with cirrhosis, impaired hepatic clearance of immune complexes leads to immunoglobulin A (IgA) nephropathy and hepatic glomerulosclerosis $(20,21)$. Even patients with wellpreserved renal function can have abnormal renal biopsies before LT (22). In one study of 18 LT recipients (22), eight patients exhibited minor glomerular abnormalities, seven had evidence of hepatic glomerulosclerosis, one had membranoproliferative glomerulonephritis and one had IgA nephropathy. The presence of these abnormalities before LT suggests that pre-existing, often asymptomatic, glomerular disease might play a role in post-transplant renal dysfunction for many patients and that the kidneys should be evaluated before surgery.

Viral infections, which are frequently encountered in patients awaiting LT, can also cause renal disease. Chronic hepatitis $\mathrm{C}$ virus (HCV) infection has been associated with type II cryoglobulinemia and membranoproliferative glomerulonephritis (21). Hepatitis B virus (HBV) has also been associated with membranous nephropathy and, in rare cases, polyarteritis nodosa (21). HCV-associated glomerulopathies have been reported in patients following LT and may be manifested by decreased renal function, proteinuria and recurrent HCV infection $(23,24)$. Renal dysfunction is not always fully reversed with antiviral therapy (23-25).

Patients with a pretransplant diagnosis of $\mathrm{HCV}$-associated glomerulopathy require a careful preoperative evaluation. In one study of six patients with membranoproliferative glomerulonephritis before LT (26), four received liver transplants while two required hemodialysis and underwent combined liver-kidney transplantation. Two of four patients treated with LT alone suffered a relapse of renal dysfunction within 17 to 36 months, while the two patients who underwent dual transplantation retained normal renal function at follow-up (26). These findings highlight the complexities of renal dysfunction in $\mathrm{HCV}$ recipients.

\section{Pretransplant renal function}

Pretransplant renal function can be a useful prognostic indicator. In one study (27), pretransplant renal insufficiency (defined as serum creatinine [SCr] greater than $142 \mu \mathrm{mol} / \mathrm{L}$ or being on dialysis) was associated with reduced patient survival $(50 \%$ versus $83 \%, \mathrm{P}=0.04)$ and allograft survival $(50 \%$ versus $71 \%)$. Patients with pretransplant renal insufficiency were more likely to have an elevated SCr at four months after transplantation and require dialysis $(\mathrm{P}<0.05)$. The cause of the decrement in patient and graft survival was unclear, but the authors of the study speculated that renal insufficiency might be a marker of more severe liver disease or the presence of other comorbidities, such as diabetes mellitus. Another study (28) that stratified patients based on pretransplant $\mathrm{SCr}$ (group 1 had pretransplant $\mathrm{SCr}$ values greater than $89 \mu \mathrm{mol} / \mathrm{L}$, whereas group 2 had $\mathrm{SCr}$ values of $89 \mu \mathrm{mol} / \mathrm{L}$ or less) yielded similar findings. Overall, ARF occurred in $23 \%$ of patients after LT, and patients in group 1 were significantly more likely to require dialysis $(52 \%$ versus $5 \%, \mathrm{P}<0.05)$ or to die $(32 \%$ versus $6 \%, \mathrm{P}<0.05)$ than those in group 2. The odds of ARF were 17.5 times higher in patients with elevated pretransplant SCr. These results suggest that assessing renal function before LT might identify a subset of patients at increased risk of ARF, graft loss and death.

\section{HRS}

HRS is defined as the development of renal failure in patients with severe acute or chronic liver disease in the absence of any other identifiable cause (29). HRS is present in $17 \%$ of patients with ascites and in more than $50 \%$ of cirrhotic patients dying from liver failure $(29,30)$. In the study by Lafayette et al $(28)$, all patients with HRS were included in group 1 and fared significantly worse than those without HRS. Another study (31), involving 294 patients, specifically examined the effect of HRS on the outcome of LT. The incidence of HRS was $10.5 \%$ and, as expected, the preoperative SCr was significantly higher and the glomerular filtration rate (GFR) significantly lower in these patients. LT resulted in a significant improvement of renal function in patients with HRS, whereas, in patients without HRS, renal function declined after transplantation, with apparent stabilization at three years. Despite a large postoperative drop in the GFR, non-HRS patients had consistently better $\mathrm{SCr}$ at all time points. Patients with HRS required more postoperative hemodialysis, but no difference was found in GFR between HRS patients who did or did not require preoperative hemodialysis one or two years after LT (Figure 1). One- and two-year patient survival tended to be lower in the HRS group. A subsequent study (32) found that HRS was associated with a significantly lower five-year survival (60\% versus $68 \%$, $\mathrm{P}<0.03$ ) and a higher incidence of ESRD (7\% versus $2 \%$ ). Renal function improved in HRS patients following LT but did not reach the level in patients without this condition.

Overall, these studies suggest that while HRS may negatively affect renal function and outcomes in LT recipients, preoperative renal function is not always a useful predictor of which HRS patients would benefit from CNI-sparing immunosuppression. The marked decrease in renal function after LT, even among patients without HRS (Figure 2) $(31,32$ ), suggests that all patients could benefit from such therapy.

\section{Post-transplant factors}

The most important cause of declining renal function following LT is probably the use of nephrotoxic immunosuppressive agents (CsA or tacrolimus) (19). In one study, among LT recipients receiving CsA-based immunosuppression (33), 


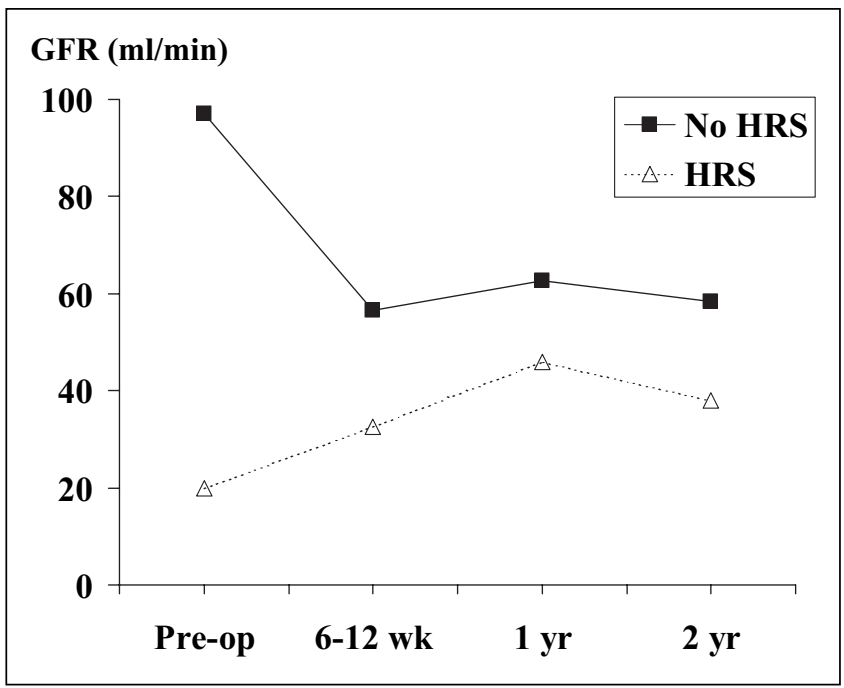

Figure 1) Preoperative (Pre-op) and one-and two-year postoperative glomerular filtration rate (GFR) in patients with hepatorenal syndrome (HRS) requiring or not requiring preoperative hemodialysis. Wk Week; Yr Year. Data from reference 31

renal dysfunction (SCr greater than $140 \mu \mathrm{mol} / \mathrm{L}$ ) was present in $20 \%$ to $25 \%(n=231)$ of patients, a proportion that remained relatively constant over five years. Hypertension was also observed in approximately $20 \%$ to $30 \%$ of these patients, with an increasing prevalence over five years. In another study of 135 patients (of whom 51 were alive five years later) followed for a mean of 7.68 years (34), renal function declined dramatically after LT, yet remained stable for up to 10 years. The proportion of hypertensive patients increased to over $80 \%$ by five years despite reductions in the CsA dosage. Hypertension was significantly associated with impaired renal function at one and five years $(\mathrm{P}<0.001)$. This study also found that preoperative creatinine clearance $(\mathrm{CCr})$ was significantly correlated with poorer post-transplant renal function $(\mathrm{P}<0.005)$ whereas preoperative SCr was not.

It is important to consider the results of these studies in light of the methods used to assess renal function. There is considerable evidence that $\mathrm{SCr}$ and $\mathrm{CCr}$ are not reliable indicators of the GFR in patients with end-stage liver disease (35-37). SCr may be significantly reduced in the presence of hepatic disease (with jaundice and deranged protein metabolism) (19) and CCr measurements may provide an artificially high assessment of the true GFR (35-37). In two studies $(31,32)$, Gonwa and colleagues followed SCr and performed isotope-measured GFR measurements for at least five years in LT patients with and without HRS. Both studies revealed a $40 \%$ decline in the GFR during the first year (mostly during the first six weeks post-transplant) among patients without HRS. Thereafter, the GFR remained stable throughout a follow-up period of four years (Figure 2).

Cohen et al (38) recently published a very comprehensive review of renal dysfunction following LT, including GFR data from 353 patients who underwent transplantation between 1990 and 1998 at a single centre. A subgroup of 191 patients had more frequent GFR measurements. Overall, the analysis confirmed previous reports that suggested that renal dysfunction is a significant problem after LT, with a cumulative incidence of renal failure (ESRD requiring dialysis or renal transplantation) of $6.25 \%$ at seven years and $10 \%$ at 10 years. It also suggested that the GFR at one

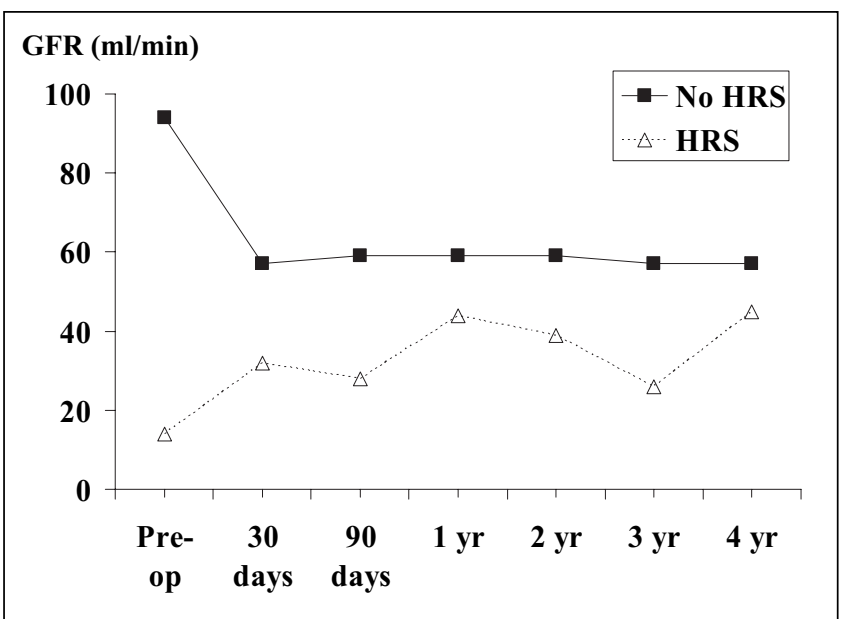

Figure 2) Evolution of pre-and post-transplant glomerular filtration rate (GFR) in liver transplant recipients with and without hepatorenal syndrome (HRS). Pre-op Preoperative; Yr Year. Data from reference 32

TABLE 1

Predictive value of one-year glomerular filtration rate (GFR) on late renal function following liver transplantation

\begin{tabular}{|c|c|c|}
\hline GFR at one year & $\mathbf{n}$ & $\begin{array}{c}\% \text { with GFR }<40 \mathrm{~mL} / \mathrm{min} / 1.73 \mathrm{~m}^{2} \\
\text { at three years }\end{array}$ \\
\hline$<40 \mathrm{~mL} / \mathrm{min} / 1.73 \mathrm{~m}^{2}$ & 26 & 65.4 \\
\hline $40-60 \mathrm{~mL} / \mathrm{min} / 1.73 \mathrm{~m}^{2}$ & 73 & 23.3 \\
\hline $60-80 \mathrm{~mL} / \mathrm{min} / 1.73 \mathrm{~m}^{2}$ & 66 & 6.6 \\
\hline$>80 \mathrm{~mL} / \mathrm{min} / 1.73 \mathrm{~m}^{2}$ & 26 & 0.0 \\
\hline
\end{tabular}

Data from reference 38

TABLE 2

Predictive value of pretransplant glomerular filtration rate (GFR) and one-year GFR in 15 patients developing endstage renal disease (ESRD)

\begin{tabular}{lc}
\hline & Patients with ESRD (\%) \\
\hline Pretransplantation GFR & \\
$>80 \mathrm{~mL} / \mathrm{min} / 1.73 \mathrm{~m}^{2}$ & 26.6 \\
$<40 \mathrm{~mL} / \mathrm{min} / 1.73 \mathrm{~m}^{2}$ & 20.0 \\
One-year GFR & \\
$>60 \mathrm{~mL} / \mathrm{min} / 1.73 \mathrm{~m}^{2}$ & 6.6 \\
$<40 \mathrm{~mL} / \mathrm{min} / 1.73 \mathrm{~m}^{2}$ & 66.0 \\
\hline
\end{tabular}

Data from reference 38

year (but not the pretransplant level) predicted long-term renal function (Tables 1 and 2), and identified a group of patients, with a GFR less than $40 \mathrm{~mL} / \mathrm{min} / 1.73 \mathrm{~m}^{2}$ at one year, who were at high risk of developing renal failure and thus, might benefit from kidney-sparing interventions. The authors also pointed out, however, that once this level of renal dysfunction (and/or associated renal fibrosis) is reached, it might be too late for such interventions to have a significant impact.

Even comprehensive GFR-based studies are of limited value in determining the possible cause of renal dysfunction in LT recipients treated with CNIs. This may be due, in part, to the lack of renal biopsy data. In one retrospective study (39), the incidence of ESRD was 3.8\%, but only one of five patients who 


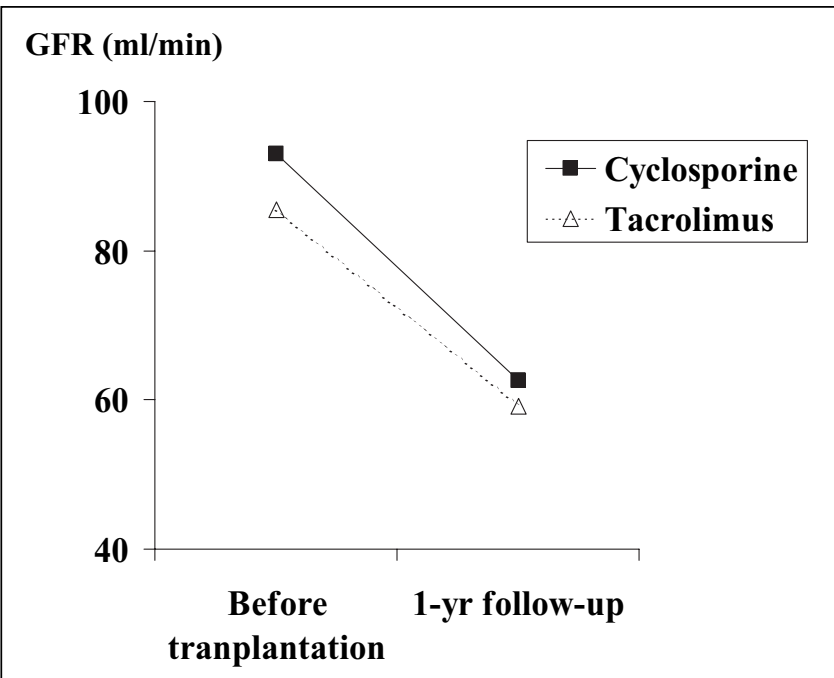

Figure 3) Evolution of pre-and post-transplant glomerular filtration rate (GFR) in liver transplant recipients treated with cyclosporine or tacrolimus. Yr Year. Data from reference 42

underwent biopsy had histological evidence of CNI-associated nephrotoxicity. Other biopsies in this series demonstrated evidence of glomerular disease. Therefore, although ongoing CNI use is clearly a risk factor for ESRD, it may not be the sole cause.

In a comparative study (40), both CsA and tacrolimus significantly reduced the GFR, with no significant difference between the two treatments in post-transplant GFR for up to 360 days, except at day 180, when the GFR was significantly lower in patients treated with tacrolimus $(\mathrm{P}=0.01)$. The decline in the GFR at one year was $52 \%$ in the tacrolimus and $36 \%$ in the CsA arms. A European comparative study (41) found that tacrolimus resulted in a significantly higher incidence of impaired renal function, although this study assessed only SCr levels. In an American multicentre study (42), both drugs caused similar changes in SCr and the GFR (Figure 3). Another study (43) also found a similar incidence of elevated SCr and decreased the GFR (evaluated by isotope clearance) at one year with CsA and tacrolimus. More importantly, this study found that $44 \%$ of patients with early (during the first three months) nephrotoxicity had persistent renal insufficiency at one year compared with $8 \%$ of patients without this complication $(\mathrm{P}<0.001)$. In another long-term, five-year follow-up study (44), SCr was comparable in CsA- and tacrolimus-treated LT patients. Overall, these studies yielded similar incidences of early post-transplant renal dysfunction among patients treated with CsA or tacrolimus.

There is controversy about whether CNI-induced acute nephrotoxicity leads to long-term renal dysfunction or lateonset renal failure. No data have directly compared the longterm GFR in patients with and without CNI-based immunosuppression, but retrospective studies $(45,46)$ suggest that ongoing CsA use is associated with progressive renal impairment. In one study of 15 heart and seven liver transplant recipients treated with $\mathrm{CsA}$ (45), there was histological evidence of progressive renal damage, including arteriolar hyalinosis and global glomerulosclerosis. There were significant associations between cumulative CsA dose and the degree of arteriolar hyalinosis $(\mathrm{P}<0.01)$ and global glomerulosclerosis $(\mathrm{P}<0.01)$. Striped interstitial fibrosis and tubular atrophy were also noted, reminiscent of chronic CsA nephrotoxicity (46). Another important finding was that calculated GFR measurements (based on SCr) did not correlate with the histological changes, and, thus, CNI-associated nephrotoxicity might not always be manifested by decrements in renal function (45).

\section{ACUTE AND CHRONIC MECHANISMS OF CNI TOXICITY}

Although the exact cause of CNI-induced nephrotoxicity is not known, several mechanisms have been implicated in the pathogenesis. Neurotoxicity is one possibility because innervation of the native kidneys is intact in LT patients. Animal studies $(47,48)$ have demonstrated that both CsA and tacrolimus increase sympathetic neuronal activity and raise arterial pressure by forming an immunophilic complex that binds to and inhibits calcineurin. Rapamycin, which does not inhibit calcineurin, lacks this effect (47). Acute, reversible, nephrotoxic effects of CsA appear to be mediated by afferent arteriolar vasoconstriction and include a reduction in the GFR and renal blood flow, and increased renal vascular resistance (49-51). Studies in healthy humans also revealed vasoconstrictive effects of CsA on the afferent arteriole. In one study (52), CsA treatment significantly decreased the GFR and increased urinary thromboxane B2 excretion. Multiple mechanisms may be involved in the vasoconstrictive effects of CsA, including alterations in prostaglandin metabolism $(49,50,53)$, increased endothelin production $(54,55)$ and reduced nitric oxide production (56-58).

The vasoconstrictive effects of CsA may cause long-term structural damage to the kidneys. Transforming growth factorbeta (TGF- $\beta$ ) is a profibrotic cytokine that has been implicated in renal fibrosis and the pathogenesis of CsA nephrotoxicity $(59,60)$. CsA has been found to induce TGF- $\beta$ expression (61), and expression of TGF- $\beta$ has been correlated with declining renal function (62). In an experimental model (63), TGF- $\beta$ mimicked and anti-TGF- $\beta$ abrogated the in vivo effects of CsA, including histopathological changes and increases in the expression of matrix proteins, collagen and fibronectin. Therapy with CsA, thus, induces acute, reversible (vasoconstrictive) and chronic, potentially irreversible (fibrotic) effects on the kidney.

In cardiac transplant patients, both low and high doses of CsA caused hypertension and azotemia, decreased the GFR and increased renal vascular resistance compared with results from patients treated without CsA (8). These effects were associated with irreversible morphological alterations, including obliterative arteriolopathy and glomerulosclerosis, which were not prevented by using lower dosages of CsA (8).

Although not as extensively studied as CsA, tacrolimus also inhibits calcineurin and produces similar morphological damage (64). Tacrolimus also induces TGF- $\beta$ expression in vitro (65), and some studies $(40,41,43)$ in LT recipients suggest that the incidences of acute and chronic nephrotoxicity are equal to or greater than those seen with CsA. The detrimental effects of CsA and tacrolimus on renal function argue against their long-term use in LT recipients, especially those with preoperative renal impairment.

Metabolic factors - Potential role in renal dysfunction Metabolic abnormalities, such as hyperlipidemia, diabetes mellitus and hypertension, are frequently observed in LT recipients and may play a role in post-transplant renal dysfunction. 
These metabolic disturbances can be attributed, in large part, to the ongoing use of immunosuppressive drugs, including steroids and CNIs $(1,2,4)$. Taking steps to minimize these adverse effects might help reduce the long-term risk of renal dysfunction.

Lipids: Both CsA and corticosteroids can induce hyperlipidemia following LT $(2,66,67)$. Switching from CsA to tacrolimus has been reported to ameliorate hyperlipidemia in renal and liver transplant patients $(68,69)$, although this finding has not been consistent in all studies. In one study of LT recipients (70), there were minimal differences in the incidence of hypercholesterolemia between CsA- and tacrolimus-treated LT patients at three, four and five years post-transplant. The overall incidence of both hypercholesterolemia and hyperlipidemia decreased with a reduction in immunosuppression, especially in the prednisone dosage.

In addition to the well-known effect of hyperlipidemia on cardiovascular risk, experimental studies (71-77) have shown that hyperlipidemia may also contribute to the decline in renal function in LT recipients. Epidemiological evidence suggests that hyperlipidemia exacerbates conditions such as diabetic nephropathy (77-79). A recent meta-analysis (77) suggested that lipid reduction therapy reduced the rate of decline in the GFR in nontransplant patients with renal disease compared with untreated patients. Overall recommendations for hyperlipidemia management in LT recipients include hepatic 3-hydroxy-3methylglutaryl coenzyme A reductase inhibitors and, if necessary, changes in immunosuppression, such as steroid withdrawal and the conversion from CsA to tacrolimus $(68,80,81)$. In patients with poor pretransplant renal function, conversion to a nonnephrotoxic agent, such as mycophenolate mofetil (MMF) or rapamycin, or the use of very low doses of tacrolimus or CsA may be viable options. Rapamycin, however, can cause hypercholesterolemia (82-84).

Hypertension: Hypertension is another troublesome consequence of $\mathrm{CNI}$ and steroid use $(1,2)$ that can lead to both posttransplant renal dysfunction and cardiovascular disease. It should be aggressively treated in LT recipients to alleviate cardiovascular risk (81). Peripheral blood monocytes from hypertensive patients produce elevated amounts of TGF- $\beta$ (85), which may contribute to hypertension-induced chronic renal damage (fibrosis). Although both CsA and tacrolimus can induce hypertension in LT patients, some evidence suggests that tacrolimus is less likely to do so. In large comparative American (42) and European trials (41), the incidence of hypertension with either drug was $35 \%$ to $56 \%$ at one year. A more recent study in LT patients (86) showed that tacrolimus-treated patients had a lower incidence of hypertension and cardiovascular events than patients treated with CsA. Nevertheless, the nephrotoxic effects observed in tacrolimus-treated patients argue against its use to reduce the risk of hypertension. Early steroid withdrawal (14 days after LT) using MMF (with CsA or tacrolimus) was found to reduce hypertension without provoking rejection in one study (80).

Diabetes mellitus: Diabetes mellitus often occurs in LT patients $(80,87,88)$ and can affect cardiovascular and long-term renal function. Post-transplant diabetes mellitus (PTDM) has been associated with the use of steroids, CsA and tacrolimus $(2,3,89)$. Intraglomerular TGF- $\beta$ levels are increased in patients with diabetes mellitus and may be associated with the progression of diabetic nephropathy $(90,91)$. Because of the potential effects of hyperglycemia on TGF- $\beta$ expression and the progression of diabetic nephropathy, blood sugar should be closely monitored after LT, and modification of the immunosuppressive regimen might be necessary. Unlike the situation in hyperlipidemia and hypertension, the risk of PTDM with tacrolimus use appears to be slightly higher than with CsA use. In a large comparative study (41), tacrolimus was associated with more hyperglycemia ( $37 \%$ versus $31 \%, \mathrm{P}<0.01)$ and diabetes mellitus $(27 \%$ versus $15 \%)$ than was CsA. In other trials $(42,92)$, however, these differences failed to reach statistical significance, and another trial (86) actually reported a trend toward a lower incidence with tacrolimus. This may have been due to differences in steroid dosing in CsA-treated patients. Steroid withdrawal after three months has been associated with reduced incidence of PTDM in LT recipients $(81,93)$.

\section{RENAL-SPARING INTERVENTIONS: IDENTIFYING PATIENTS AT RISK}

Under ideal conditions, a comprehensive renal assessment before LT should include a SCr measure, $24 \mathrm{~h}$ urine collection for CCr and protein measures, assessment for microalbuminuria and urinary sediment, renal ultrasound, radionuclide GFR, measurement of effective renal plasma flow and, possibly, a renal biopsy. Unfortunately, many of these tests are costly, time-consuming and/or invasive, and are difficult to justify for patients who present with normal preoperative renal function. In addition, there is no consensus about identifying patients who are at greatest risk for renal dysfunction after transplantation or even those who would benefit from combined liverkidney transplantation, although preliminary guidelines and algorithms have been proposed (94). It is beyond the scope of the present review to discuss all the factors involved in selecting patients for dual transplantation. Suffice it to say that this approach remains a viable intervention for selected patients, as does sequential (renal-after-liver) transplantation.

It is difficult to evaluate renal function in patients with hepatic failure. Patients may present with no apparent preoperative renal impairment or they may have pre-existing asymptomatic glomerular disease that can dramatically affect renal function after transplantation. Short-term and, especially, long-term measurements of renal function, however, are insufficient to reliably predict a given patient's course. Ongoing assessments are necessary. Inulin clearance is the gold standard for measuring the GFR, but isotope techniques are costly and time-consuming. $\mathrm{SCr}$ or $\mathrm{CCr}$ measurements are more readily available but are less accurate estimates of the true GFR.

Among the available alternatives to isotope GFR measurement, the calculated CCr appears to be the most reliable. In heart transplant patients, it was observed that calculated $\mathrm{CCr}$ correlates best with the GFR $\left(\mathrm{r}^{2}=0.65\right)$ compared with CCr $\left(\mathrm{r}^{2}=0.53\right)$ and $\mathrm{SCr}\left(\mathrm{r}^{2}=0.38\right)(95)$.

It was recently demonstrated that cimetidine, by virtue of its ability to decrease the tubular secretion of creatinine, can further improve the accuracy of SCr, $\mathrm{CCr}$ and calculated $\mathrm{CCr}$ measurements in heart transplant patients (96). The correlation between the radionuclide-evaluated GFR and each of the markers, using cimetidine, was again highest for calculated $\mathrm{CCr}$ $\left(\mathrm{r}^{2}=0.75\right)$ compared with CCr $\left(\mathrm{r}^{2}=0.72\right)$ or SCr $\left(\mathrm{r}^{2}=0.68\right)$, and the use of cimetidine was highly cost-effective compared with isotope techniques $(\$ 0.48$ versus $\$ 60.00)$. A similar study is underway in LT patients. Accordingly, a strategy for incorporating calculated CCr into daily practice is being investigated. Its adoption is more likely to identify patients with declining renal 
function before significant deterioration occurs. Regimens that preserve renal function can then be implemented, aimed at improving long-term prognosis, particularly in view of the recent finding that the one-year GFR predicts long-term renal function (38).

It should be emphasized, however, that these methods for estimating the GFR have not been rigorously established in LT patients. As described in a recent overview by McClellan (97), the Cockcroft-Gault and modification of diet renal disease equations for the calculation of the GFR do not appear to be universally applicable to large populations. For example, raceand sex-based differences were observed in estimates of the prevalence of chronic kidney disease in the United States $(97,98)$. It seems prudent, therefore, to confirm the correlation between SCr-based formulas and the isotope GFR in LT patients. Until such correlation becomes available, the isotope GFR should be considered a more appropriate assessment of renal function in LT patients.

The kidneys play an important role in the metabolism of low molecular weight proteins. Serum levels of cystatin C $(13 \mathrm{kDa})$ are significantly increased by small reductions in the GFR $(99,100)$. There is growing evidence that serum cystatin $\mathrm{C}$ has an excellent correlation with the isotope GFR. Mussap et al (101) employed a nephelometric immunoassay procedure in a study of 52 patients with type II diabetes mellitus, and showed that plasma cystatin $\mathrm{C}$ was more accurate than either the $\mathrm{SCr}$ or the Cockcroft-Gault equation in estimating the GFR (100). Cystatin $\mathrm{C}$ was the best diagnostic method to identify diabetic patients with normal or reduced (less than $80 \mathrm{~mL} / \mathrm{min} / 1.73 \mathrm{~m}^{2}$ ) GFR (eg, specificity and sensitivity, respectively). Future studies will be required to determine whether this test yields similar sensitivity and specificity in LT patients.

\section{STRATEGIES TO IMPROVE RENAL FUNCTION IN LT}

\section{Combined liver-kidney transplantation}

Dual transplantation or pre-emptive renal-after-liver transplantation might be a viable option for some LT patients with documented pre- or post-transplant renal disease, respectively. In a recent publication (94), preliminary guidelines and algorithms have been proposed for combined liver-kidney transplantation. Polycystic liver disease can occur with polycystic kidney disease, especially if they require dialysis (102-104). At our own centre (McGill University Health Centre, Montreal), two combined liver-kidney transplantations have been performed for this indication (unpublished data). It has been suggested that patients with polycystic liver disease who are not dialysis-dependent might undergo LT, followed by renal transplantation if necessary (103). Other indications for dual transplantation include diabetic nephropathy, glomerulonephritis and congenital pyelonephritis (105). One-year survival rates of $75 \%$ have been achieved, with good hepatic and renal function (105).

Some renal disorders, such as cirrhotic (106), HBV- and HCV-associated glomerulonephritis $(107,108)$ can be ameliorated by LT. Rapid resolution of glomerulonephritis is associated with diminished levels of circulating HBV surface antigen.

\section{New immunosuppressive options}

For patients for whom combined liver-kidney transplantation or renal-after-liver transplantation is not indicated or feasible, other treatment options must be sought to reduce the risk of post-transplant renal dysfunction. Several new immunosuppressive medications have been introduced, some of which are safer for the kidneys. Although tacrolimus may have less impact on blood pressure and serum lipids than CsA (86), both drugs carry a risk of nephrotoxicity (Figure 3) (40,42,43). Replacing CNIs with non-nephrotoxic agents has, therefore, been investigated as a possible way of preserving renal function. MMF: MMF is a prodrug of mycophenolic acid, which is a reversible noncompetitive inhibitor of inosine monophosphate dehydrogenase, an enzyme required for purine biosynthesis (109). The predominant mode of action of MMF is suppression of lymphocyte DNA synthesis and arrest in the $\mathrm{S}$ phase of the cell cycle $(110,111)$. In vitro studies $(111,112)$ also suggest that inhibition of purine biosynthesis by MMF results in reduced expression of lymphocyte cell surface molecules and endothelial receptors, which may be important in blocking lymphocyte homing to sites of allograft rejection. In addition to these immunosuppressive effects, an experimental study (113) suggests that MMF prevents renal injury, including glomerulosclerosis, tubular atrophy and interstitial fibrosis. The reduction of interstitial fibrosis by MMF may relate, in part, to its inhibitory effects on fibroblast proliferation $(114,115)$.

The safety and efficacy of MMF in reducing the risk of acute rejection has been established in large multicentre trials of renal and cardiac allograft recipients (116-120). A randomized double-blind trial (121) involving 565 LT recipients compared the efficacy and safety of MMF with azathioprine when used in combination with CsA and steroids. MMF-treated patients had a significantly lower incidence of acute rejection (38.5\% versus $47.7 \%, \mathrm{P}<0.03)$ and of steroid-resistant rejection $(3.8 \%$ versus $8.2 \%, \mathrm{P}<0.02)$ than those treated with azathioprine (121). Unlike the CNIs, MMF does not exhibit nephrotoxic, hypertensive or hyperlipidemic effects (109). The predominant adverse events are gastrointestinal disturbances (nausea, vomiting, abdominal pain and diarrhea) and bone marrow toxicity $(116,118)$.

Mammalian target of rapamycin inhibitors: Sirolimus (rapamycin) and its derivative, everolimus, are members of a new class of immunosuppressive drugs that inhibit the mammalian target of rapamycin (mTOR) (84). Unlike CsA and tacrolimus, these drugs do not inhibit calcineurin or $\mathrm{T}$ cell activation. Rather, their principal mode of action is at the effector level. mTOR is necessary for progression through the cell cycle, and, thus, inhibition of mTOR by this class of drugs blocks the proliferative responses of $\mathrm{T}$ and $\mathrm{B}$ lymphocytes (84). The safety and efficacy of sirolimus has been demonstrated in large trials of renal allograft recipients $(82,83)$, and an early (phase I) study (122) has shown the safety and tolerability of everolimus in LT recipients. A recent study (123) compared everolimus with azathioprine in heart transplant recipients who also received CsA and steroids. In this study, patients treated with everolimus had lower acute rejection rates and CsA dosages than those given azathioprine. On the other hand, serum lipids (triglycerides and cholesterol) and SCr levels were significantly higher in everolimus-treated patients. The potential benefits of this therapy in LT recipients remain to be seen.

Despite its potential clinical advantages, the safety and efficacy of sirolimus have not been established in LT recipients, although it is currently indicated for renal transplants in combination with CsA and steroids (124). The effectiveness of sirolimus in LT has been reviewed in two recent publications $(125,126)$. There are no studies in LT patients comparing 
sirolimus with conventional immunosuppression (125). The efficacy of sirolimus in LT was reported in four open-label studies. The incidence of acute rejection ranged from $0 \%$ to $75 \%$ and patient survival ranged from $66 \%$ to $93 \%(125,127-129)$. SCr levels remained stable, ranging between $80 \mu \mathrm{mol} / \mathrm{L}$ and $98 \mu \mathrm{mol} / \mathrm{L}$ one month after, and between $102 \mu \mathrm{mol} / \mathrm{L}$ and $107 \mu \mathrm{mol} / \mathrm{L}$ one year after, transplantation $(125,128,129)$.

The predominant side effects of sirolimus are hyperlipidemia, thrombocytopenia, acne, skin rash, peripheral edema, arthralgias, oral ulcers, interstitial pneumonitis, infections, decreased wound healing, gastrointestinal complaints and hypercoagulability $(82-84,126)$. Moreover, a recently issued black box warning also stated that the use of sirolimus with CsA or tacrolimus in LT patients had been associated with an increased incidence of hepatic artery thrombosis, which usually resulted in graft loss or death (130). Based on the reported incidence of side effects, the use of sirolimus needs to be reassessed in LT. Future research should focus on determining the best immunosuppressive regimen and on optimizing therapeutic drug monitoring. A delayed initiation of sirolimus after transplantation (eg, two weeks) might reduce the risk of hepatic artery thrombosis and decreased wound healing.

\section{Preventive strategies: CNI delay}

An alternative means to avert renal failure in the posttransplant period is to delay or interrupt CNI use until renal function improves. At the McGill University Health Centre, Montreal, a trial was conducted using antithymocyte globulin (ATG) to delay the introduction of CNI therapy in patients with postoperative ARF requiring hemodialysis (131). Patients in group $1(\mathrm{n}=33)$ required hemodialysis and received ATG, those in group $2(\mathrm{n}=207)$ did not require hemodialysis and received ATG, and those in group $3(n=63)$ did not require hemodialysis and did not receive induction therapy. Patients were maintained on prednisone with azathioprine or MMF. Patients in group 1 received ATG every two to five days, and CNI therapy was delayed until renal function recovered; in groups 2 and 3, patients received CNIs when SCr stabilized. ATG allowed a delay in CNI therapy without increasing the risk of acute rejection. Patients with postoperative ARF requiring hemodialysis had an increased risk of mortality and ESRD requiring chronic hemodialysis (131).

Anti-CD25 monoclonal antibody (daclizumab) has also been used to delay the introduction of CNI therapy in a study of 25 patients with renal impairment ( $\mathrm{SCr}$ greater than $178 \mu \mathrm{mol} / \mathrm{L}$ ) before LT (132). Patients were treated with daclizumab, MMF and prednisone, and tacrolimus was added after renal function improved (when SCr levels decreased by greater than $25 \%$ of the initial value). Historical controls were similar groups of patients treated with OKT3 $(n=56)$ or low dose tacrolimus $(n=48)$. SCr after three months and one year were similar among the groups, but the requirement for dialysis was lower in the daclizumab group (4\%) than in the OKT3 and tacrolimus groups (23\% and 27\%, respectively). Daclizumab-treated patients had fewer infectious complications, and daclizumab was superior to tacrolimus in terms of patient and graft survival at two years (89\% versus $73 \%$ and $81 \%$ versus $69 \%$, respectively). Other studies have yielded less favourable results. A pilot study (133) in LT patients with daclizumab induction, with steroids and MMF, and no initial CNI, was halted because all seven patients experienced rejection. The 25 patients outside of the pilot study who received the same therapy but with CNI therapy, generally within the first postoperative week, had a markedly lower rejection rate (36\%). It should be noted that subtherapeutic levels of daclizumab might have contributed to the poor outcomes in this study. Further studies are needed to determine the optimal dosage regimen and use of daclizumab in this setting.

\section{Preventive strategies: CNI therapeutic drug monitoring}

The optimal doses and combinations of immunosuppressive drugs for maintenance therapy following LT have not been firmly established. Therapeutic drug monitoring has been investigated as a means of optimizing CNI therapy. It has previously been shown that, compared with trough levels (CO), whole blood CsA (Neoral; Novartis Pharmaceuticals, Canada) levels at $2 \mathrm{~h}$ post-dose $(\mathrm{C} 2)$ are better correlated with the area under the curve (AUC) from $0 \mathrm{~h}$ to $4 \mathrm{~h}(134,135)$. In LT recipients, Neoral dose monitoring using a 'low' C2 target level (300 ng/mL to $600 \mathrm{ng} / \mathrm{mL}$ ) was associated with a clinical benefit (no rejection and no increase in SCr) in $82 \%$ of patients compared with $23 \%$ of those monitored using a 'high' $\mathrm{C} 2$ target level (700 ng/mL to $1000 \mathrm{ng} / \mathrm{mL}$ ) or $37.5 \%$ of patients monitored using CO (target level $100 \mathrm{ng} / \mathrm{mL}$ to $200 \mathrm{ng} / \mathrm{mL}$ ) (135). Calcineurin inhibition was similar in all groups, suggesting that higher $\mathrm{C} 2$ levels were probably not necessary to inhibit calcineurin in long-term LT patients. Similar observations have been made in stable heart transplant recipients switched from Sandimmune (Novartis Pharmaceuticals, Canada) to Neoral (134). In both of these studies $(134,135)$, $\mathrm{C} 2$ was better correlated with AUC from $0 \mathrm{~h}$ to $4 \mathrm{~h}$ than was $\mathrm{CO}$. C2 measurement using the 'low' target range in LT recipients can, therefore, provide adequate prophylaxis with lower risk of renal dysfunction (135). In a study of 309 LT recipients (136), C2 monitoring was associated with a lower overall incidence of rejection and of biopsy-proven rejection, and a significantly lower incidence of moderate to severe histological abnormalities ( $47 \%$ versus $73 \%, \mathrm{P}=0.01$ ) than $\mathrm{C} 0$ monitoring. During the first 12 weeks after transplantation, there were no differences in the incidence of ARF between the $\mathrm{C} 2$ and $\mathrm{CO}$ groups. Extended follow-up is required to determine the potential benefit of $\mathrm{C} 2$ monitoring on long-term renal function in these patients (137).

Tacrolimus is a more potent immunosuppressant than CsA, and therapeutic whole blood trough levels are approximately 20-fold lower (138). At least three studies in LT patients have failed to find an association between tacrolimus trough levels and rejection rates (139). Results from a single-centre study (140), however, suggested an enhanced risk of rejection at tacrolimus levels below $5 \mathrm{ng} / \mathrm{mL}$ in LT patients. There appears to be a consistent relationship between toxicity and elevated tacrolimus trough levels $(138,139,141,142)$, suggesting that therapeutic drug monitoring of tacrolimus, like CsA, might be useful in LT patients. Recommended tacrolimus doses in the initial post-transplant period are $10 \mathrm{ng} / \mathrm{mL}$ to $15 \mathrm{ng} / \mathrm{mL}$, and $5 \mathrm{ng} / \mathrm{mL}$ to $10 \mathrm{ng} / \mathrm{mL}$ for maintenance $(138,141)$. Nevertheless, renal dysfunction has been observed even in patients with tacrolimus trough levels below this 'therapeutic' range (0.5 ng/mL to $3.0 \mathrm{ng} / \mathrm{mL}$ ) (Figure 3) (40), suggesting that improvements in monitoring methods and/or a re-evaluation of target levels are needed. It has been previously reported that $2 \mathrm{~h}, 3 \mathrm{~h}$ and $4 \mathrm{~h}$ postdose tacrolimus levels correlate better with an abbreviated AUC ( $(0 \mathrm{~h}$ to $6 \mathrm{~h})$ in LT patients than do trough levels (CO) (143). Future studies are needed to confirm the 
results with the AUC from $0 \mathrm{~h}$ to $12 \mathrm{~h}$ and to evaluate a different time point (eg, C2) for therapeutic drug monitoring of tacrolimus. With additional refinements in therapeutic drug monitoring for CsA and tacrolimus, it is plausible that efficacy could be maintained with a lower incidence of adverse effects such as nephrotoxicity.

\section{Preventive strategies: CNI withdrawal and CNI dose reduction}

The significant risk of rejection after withdrawal of CsA or tacrolimus must be weighed carefully against the potential benefit of improved renal function. In one CsA withdrawal study using an azathioprine/steroid regimen (144), only a minimal decrease in SCr $(222 \mu \mathrm{mol} / \mathrm{L}$ to $214 \mu \mathrm{mol} / \mathrm{L})$ was observed at 18 months. Six of 12 patients experienced acute rejection, and only some of these were permanently reversed with steroid therapy. These results underscore the importance of effective antirejection prophylaxis during CNI withdrawal. MMF has proven more effective than azathioprine for the prevention of acute rejection in large studies of renal transplant patients $(116,118)$ and more recently, in LT patients $(121)$.

A number of recent studies (145-147) has investigated the use of MMF as a CNI-sparing agent. A small, uncontrolled study (145) of five stable LT recipients with CsA-induced renal impairment found that the introduction of MMF was associated with an improvement in renal function at three months (fall in median SCr from $201 \mu \mathrm{mol} / \mathrm{L}$ to $142 \mu \mathrm{mol} / \mathrm{L}, \mathrm{P}=0.04$ ) and six months (SCr $139 \mu \mathrm{mol} / \mathrm{L}$, $\mathrm{P}=0.04$ ). Rejection occurred in one of the five patients after three months of monotherapy, which was reversed by steroids.

MMF was also used to slowly reduce or discontinue CsA in a study of 11 stable LT recipients who were free from rejection for at least one year (146). By the end of the study (mean follow-up of 63 weeks), seven of the 11 patients (64\%) were completely free from CsA and six of the seven were also free from steroids. Two of 11 patients (18\%) developed mild rejection that responded to tacrolimus. In the seven patients successfully converted to MMF, renal function significantly improved (SCr fell from $196.5 \mu \mathrm{mol} / \mathrm{L}$ to $168.2 \mu \mathrm{mol} / \mathrm{L}$, $\mathrm{P}=0.05$ ) and $\mathrm{CCr}$ increased from $0.64 \mathrm{~mL} / \mathrm{s}$ to $0.78 \mathrm{~mL} / \mathrm{s}$, $\mathrm{P}=0.005$ ). Control of hypertension in these seven patients also improved, reflected by a significant decrease in their use of antihypertensive medications $(\mathrm{P}=0.005)$ and a trend toward lower systolic and diastolic blood pressures. Serum triglyceride levels decreased significantly (from $2.45 \mathrm{mmol} / \mathrm{L}$ to $1.77 \mathrm{mmol} / \mathrm{L}, \mathrm{P}=0.02$ ), and there was a trend toward lower total cholesterol levels (from $2.28 \mathrm{mmol} / \mathrm{L}$ to $2.11 \mathrm{mmol} / \mathrm{L}$ ). In two other patients, the dosage of CsA was reduced by $50 \%$, with a modest improvement in renal function.

In a study of 28 patients with suspected CNI-related toxicity at least six months post-transplant (142), CNI therapy was either continued or withdrawn in a stepwise manner using MMF. Renal function improved significantly in the MMF group at six months ( $\mathrm{SCr}$ fell by $44.4 \mu \mathrm{mol} / \mathrm{L}, \mathrm{P}=0.001$ ), but did not change in the control group (SCr fell by only $3.1 \mu \mathrm{mol} / \mathrm{L}, \mathrm{P}=0.440$ ). There was also an improvement in $\mathrm{CCr}$ of $0.14 \mathrm{~mL} / \mathrm{s}$ in the MMF group compared with a decline of $0.1 \mathrm{~mL} / \mathrm{s}$ in the control group during the same period. Systolic and diastolic blood pressure, and uric acid decreased significantly in the MMF group, and there were no changes in serum lipids at six months. Rejection was diagnosed in three of 14 patients in the MMF group compared with none in the control group; all of these patients, however, regained normal liver function by six months. The most frequent adverse events from MMF were gastrointestinal and hematological $(146,147)$. The conversion from a CNI- to a sirolimus-based regimen resulted in an improvement in renal function in LT patients $(148,149)$. In one study (148), conversion from tacrolimus- to sirolimus-based immunosuppression in $16 \mathrm{LT}$ patients who were greater than three years post-transplant, resulted in an improvement in SCr levels $(174 \mu \mathrm{mol} / \mathrm{L}$ to $134 \mu \mathrm{mol} / \mathrm{L}, \mathrm{P}=0.001)$ and there was a trend toward an improvement in the $\mathrm{CCr}(0.72 \mathrm{~mL} / \mathrm{s}$ to $0.82 \mathrm{~mL} / \mathrm{s})$ without evidence of acute rejection. Sirolimus was discontinued in four patients (25\%) because of oral ulcers. In another study (149), sirolimus replaced CNI in $21 \mathrm{LT}$ patients (tacrolimus in eight patients and CsA in 13 patients), nine to 780 weeks after transplantation. Monotherapy was employed in 18 patients and combination therapy with corticosteroids in three patients. This strategy resulted in an improvement in the calculated GFR $\left(34 \mathrm{~mL} / \mathrm{min} / 1.73 \mathrm{~m}^{2}\right.$ to $43 \mathrm{~mL} / \mathrm{min} / 1.73 \mathrm{~m}^{2}, \mathrm{P}=0.001$ ) at 67 weeks of follow-up. Acute rejection was observed in one patient. Side effects were observed in 12 patients (57\%). Sirolimus was discontinued in two patients (9.5\%) because of oral ulcers and interstitial pneumonitis.

Overall, CNI withdrawal using MMF or sirolimus has been shown to improve renal function in LT patients. It seems that a lower acute rejection rate was observed after conversion to sirolimus than with MMF, and acute rejection episodes were reversible. Long-term follow-up of larger numbers of patients will be needed to determine the safety of these regimens.

\section{POTENTIAL STRATEGIES TO PREVENT OR TREAT RENAL DYSFUNCTION IN LT}

\section{Novel combination therapies}

Combinations of new immunosuppressive agents with CNIs might permit a reduction in CNI dosage and minimize CNIassociated adverse effects. In a randomized comparative study involving 350 patients (150), tacrolimus was combined with steroids alone (double therapy) or steroids plus MMF (triple therapy). Similar patient and graft survival rates were observed in the two groups for up to four years. There was a significantly lower incidence of rejection in the MMF (triple therapy) group at three months and a trend toward less rejection at one year. However, MMF was discontinued in 103 of 175 patients (59\%), and nearly all occurred within the first year. Mean steroid dosage was $4 \%$ to $12 \%$ lower in MMFtreated patients, and there was a trend toward more patients being off steroids by two years in this group. Tacrolimus dosages were comparable between the groups, but the mean rise in SCr tended to be lower in the triple therapy group. Significantly fewer previously nondialyzed patients in the triple group required post-transplant hemodialysis (23\% versus $11 \%, \mathrm{P}=0.007$ ). It is unclear from this trial whether reduced tacrolimus dosing in the triple therapy group might have further improved renal function or would have led to fewer MMF discontinuations.

Sirolimus has also been used in combination with MMF in a small study of 14 LT recipients with renal insufficiency or mental status impairment (151). Sirolimus, MMF and steroids were used until these conditions improved before the introduction of tacrolimus. During the two- to sevenmonth follow-up period, six of nine patients in whom CNI therapy was ultimately withheld experienced rejection, with one requiring antilymphocyte therapy. SCr levels decreased from $196 \mu \mathrm{mol} / \mathrm{L}$ to $107 \mu \mathrm{mol} / \mathrm{L}$ by three months, and in 
three patients with neurological complications, their mental status returned to normal.

FTY720 is a novel immunosuppressant that exerts its effect through the apoptotic depletion of activated lymphocytes $(152,153)$ and the impairment of effector T cell homing (147). Because its mechanism of action is distinct from those of CNIs, MMF and mTOR inhibitors, FTY720 may be useful in combination with low doses of these or other immunosuppressives (154). Experimental studies (155-157) thus far suggest that it acts in a synergistic fashion with CsA, tacrolimus and sirolimus. It remains to be seen whether these combinations will be useful in preventing rejection while minimizing toxicity.

\section{Low dose or ultra low dose CNI}

The use of very low dose CNI therapy has also been investigated as a means of preserving renal function after LT. The efficacy of a regimen where MMF ( $1 \mathrm{~g}$ twice/day) was used to taper the CsA dose to $25 \mathrm{mg}$ twice/day (without steroids) was investigated in 19 LT recipients at least one year after transplantation (158). All of these patients had renal dysfunction, with CCr less than $25 \%$ of the values at the first postoperative month. In this trial, the incidence of acute rejection following therapeutic intervention was $29 \%$, and rejections were reversible in all but one case, where the patient was nonadherent and had discontinued MMF. SCr, CCr and the GFR were significantly improved at one year after the intervention (Figure 4). Antihypertensives were discontinued in $71 \%$ of patients and, despite a reduction in CsA levels, there were no changes in serum TGF- $\beta$ levels or in calcineurin inhibition. Overall, the intervention was well tolerated, with gastrointestinal side effects and leukopenia occurring in 18\% and 24\% of patients, respectively. These events resolved with reduction of the MMF dosage.

The use of very low dose CsA in combination with MMF or perhaps sirolimus is worthy of further investigation in LT patients. In renal transplant patients, the combination of sirolimus, MMF and steroids resulted in better renal function (SCr and the GFR) than did the use of CsA, MMF and steroids (159). In this study, the incidence of rejection was not significantly different between the regimens, although it tended to be higher in the sirolimus arm. In another study of renal transplant recipients (160), SCr and the GFR were significantly improved following the withdrawal of CsA at three months from a regimen of CsA, sirolimus and steroids, together with an increase in sirolimus dosage. These results suggest that sirolimus, at least in renal transplant patients, might be most appropriate when used in the absence of CsA, because the combination of the two drugs appears to exacerbate the nephrotoxic effects of CsA. The efficacy and safety of combining sirolimus with low or very low dose CNIs need to be established.

A retrospective comparative study (161) was done with 130 LT patients who were given either tacrolimus $0.15 \mathrm{mg} / \mathrm{kg}$ twice/day $(\mathrm{n}=80)$ and a tapering schedule of steroids or tacrolimus $0.10 \mathrm{mg} / \mathrm{kg}$ twice/day, steroids and MMF. In this study, MMF was tapered and discontinued after three months. Overall, the incidence of rejection was lower (26\% versus $45 \%$, $\mathrm{P}=0.03)$, as were tacrolimus doses at six months $(11.6 \mathrm{ng} / \mathrm{mL}$ versus $8.2 \mathrm{ng} / \mathrm{mL}, \mathrm{P}=0.0001$ ) in the MMF group. Moreover, steroid tapering was accomplished more rapidly in the MMF group, leading to lower steroid dosages at all time points. The lower tacrolimus dosages in the MMF group allowed for significantly

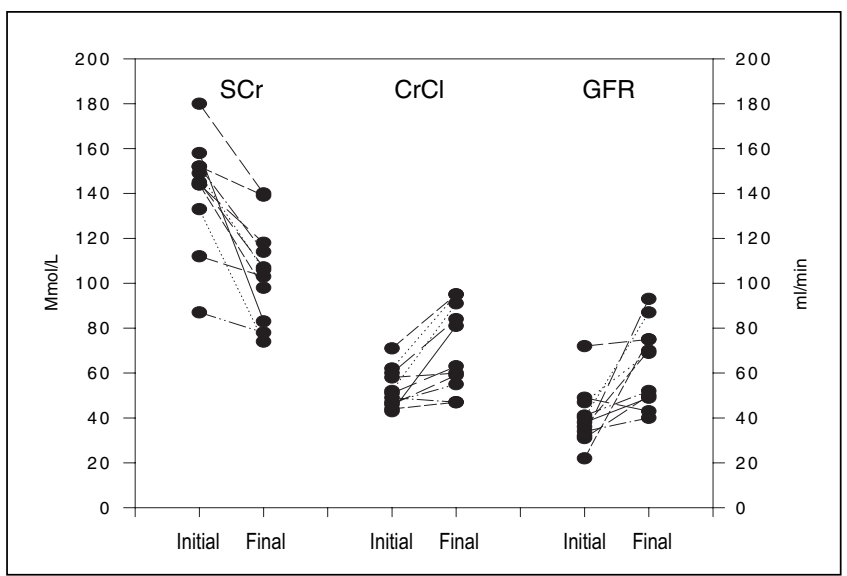

Figure 4) Evolution of renal function in long-term liver transplant patients on mycophenolate mofetil with very low dose cyclosporine. $\mathrm{CrCl}$ Creatinine clearance; GFR Glomerular filtration rate; $\mathrm{SCr}$ Serum creatinine. Data from reference 158

better preservation of early renal function at one month (SCr $97 \mu \mathrm{mol} / \mathrm{L}$ versus $134 \mu \mathrm{mol} / \mathrm{L}, \mathrm{P}=0.0001$ ). Thus, early use of MMF might allow for lower dosing of tacrolimus and steroids, and the associated benefits.

Sirolimus was studied in combination with low dose tacrolimus in 56 LT recipients (128). Patient and graft survival during 23 months of follow-up were $93 \%$ and $91 \%$, respectively. The acute rejection rate was $14 \%$ and the incidence of hepatic artery thrombosis was $1.8 \%$. Renal function, glucose control and lipid levels were near normal in $84 \%$ of the patients without additional medication, and $91 \%$ of the patients were also withdrawn from steroids. The safety and efficacy of this regimen remain to be tested in a randomized controlled trial, especially considering the occurrence of hepatic artery thrombosis. In view of the known effects of sirolimus on lipid metabolism $(82,83)$, it is noteworthy that its use in the context of a tacrolimus-based, prednisone-free regimen has not been associated with this adverse effect, whereas the same does not appear to be true for CsA (162). Serum triglyceride levels were more than twofold greater in CsA-treated patients than those given tacrolimus under this regimen, and hypercholesterolemia was significantly more prevalent with CsA (30\% versus $6 \%$, $\mathrm{P}<0.05)$ (156). CsA might be better given with either MMF or FTY720. The use of CsA or tacrolimus in combination with FTY720 is under investigation, and early results show a strong synergy among these agents (155-157). Such combinations might allow for further reductions in CNI dosing and fewer adverse effects.

\section{Temporary CNI discontinuation ('Holiday')}

Temporary CNI discontinuation may be necessary in LT patients experiencing acute renal dysfunction after the initial postoperative course. The goal is to temporarily discontinue the use of CNI (ie, provide a 'drug holiday') and allow renal function to recover. The safest strategy remains to be determined: temporary discontinuation of CNI under anti-CD25 monoclonal antibody coverage (163), temporary discontinuation of CNI without changing the baseline immunosuppressive regimen (either azathioprine with/without steroids, or MMF with/without steroids) or the addition of rapamycin. 


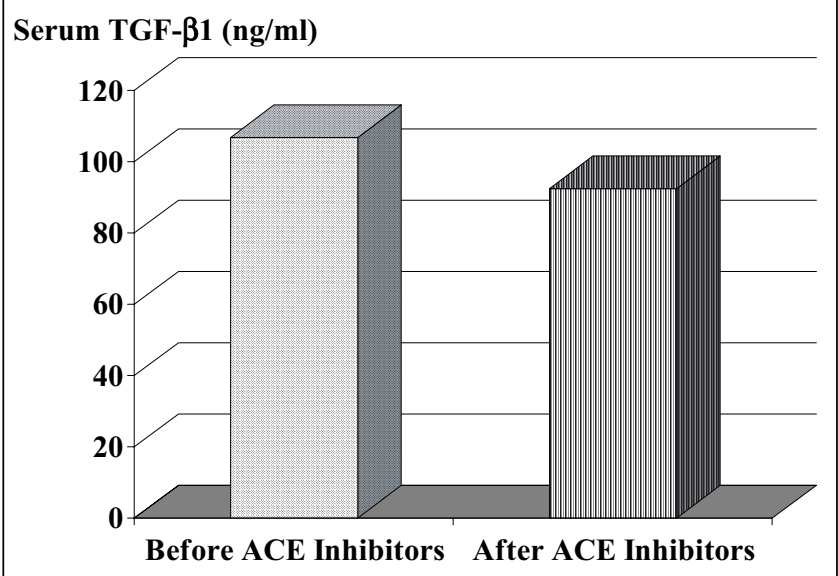

Figure 5) Effect of angiotensin-converting enzyme (ACE) inhibitor therapy on renal transforming growth factor-beta (TGF- $\beta$ ) expression in patients with various types of glomerulonephritis (mainly immunoglobulin A nephropathy). Data from reference 170

\section{Therapies to prevent renal damage: TGF- $\beta$ and inhibitors of the renin-angiotensin system}

Some analyses have suggested that polymorphisms in the genes for the renin-angiotensin system affect susceptibility to renal dysfunction. Among renal transplant recipients, variations in angiotensin-converting enzyme (ACE), angiotensinogen and aldosterone synthase genotypes have been associated with differences in susceptibility to graft loss and/or stability of renal function over time (164-167). In addition, variations in the type 1 angiotensin receptor have been associated with increased diastolic blood pressure (166). Whether pretransplantation genetic testing will prove useful in the setting of LT remains to be seen.

TGF- $\beta$ expression has been correlated with renal fibrosis, CsA toxicity and declining renal function $(59,60,62)$. Inhibition of TGF- $\beta$ expression, through the blockade of the renin-angiotensin system, has been investigated as a possible means of ameliorating potentially irreversible kidney damage (168-170). An experimental study(171) suggested that combined ACE inhibitor and angiotensin II receptor antagonist therapy could reverse progressive renal damage in a rat model of spontaneous overt nephropathy. Angiotensin II antagonist therapy normalized proteinuria, prevented infiltration of inflammatory cells and reversed structural changes in glomeruli and tubules (171). Recent clinical studies support these findings. In one study of 39 patients with IgA nephropathy (170), ACE inhibitors significantly decreased renal TGF- $\beta$ levels $(P<0.05)$ (Figure 5). In contrast, there was no difference in renal TGF- $\beta$ levels between patients on ACE inhibitors and healthy controls or those on calcium channel blockers (Figure 5). Renal expression of TGF- $\beta$ was also higher in transplant patients with CsA-associated nephropathy than in nephrectomy specimens $(\mathrm{P}<0.0001)(172)$. Patients on ACE inhibitor therapy for hypertension, however, showed significantly less TGF- $\beta$ expression $(\mathrm{P}<0.05)$. Because ACE inhibitors are commonly used to reduce blood pressure, it may be necessary to modify the therapy so that reducing TGF- $\beta$ levels becomes the therapeutic target to prevent renal damage induced by CNIs (168). Large prospective studies are needed to determine whether TGF- $\beta$ reduction would be effective in preventing CNI-induced renal dysfunction in LT patients. It will also be of great interest to ascertain the value of such therapies in further reducing the risk of renal dysfunction when combined with other strategies outlined in the present review.

\section{CONCLUSIONS}

Renal impairment is a significant problem following LT, associated with complications, and poor graft and patient survival. Several factors, including pretransplant renal dysfunction (eg, pre-existing renal disease and HRS), contribute to ARF and ESRD following LT. Post-transplant factors, including the use of either CsA or tacrolimus, have also been associated with nephrotoxicity. CNIs also cause hypertension, diabetes and hyperlipidemia, which adversely affect renal function and increase cardiovascular risk. Withdrawal or reduction of the dosage of CNIs is, therefore, a viable therapeutic option to correct these metabolic disturbances but may be accompanied by a significant risk of rejection. Alternatively, improvements in therapeutic drug monitoring may help identify optimal dosages and combinations of CNIs that adequately prevent rejection without provoking major adverse effects. Experimentation with low dose CNI therapy in conjunction with newer agents (eg, MMF and sirolimus) has shown promise in improving renal function and metabolic parameters in LT patients. A delay in CNI administration, using antibody therapy (eg, ATG or anti-CD25), or temporary CNI discontinuation ('drug holiday'), using anti-CD25 monoclonal antibodies, may also be safe and effective ways of improving renal function following ARF. Medications that may prevent the development of fibrosis secondary to CNI (eg, TGF- $\beta$ inhibitors, angiotensin II inhibitors or angiotensin II receptor blockers) may also be useful.

\section{REFERENCES}

1. Vanrenterghem Y. Strategies to reduce or replace steroid dosing. Transplant Proc 1999;31:7S-10S.

2. Danovitch GM. Immunosuppressant-induced metabolic toxicities. Transplant Rev 2000;14:65-81.

3. Gonwa TA. Hypertension and renal dysfunction in long-term liver transplant recipients. Liver Transpl 2001;7(Suppl 1):S22-6.

4. Rabkin JM, de La Melena V, Orloff SL, Corless CL, Rosen HR, Olyaei AJ. Late mortality after orthotopic liver transplantation. Am J Surg 2001;181:475-9.

5. Bennett WM, De Mattos A, Meyer MM, Andoh T, Barry JM. Chronic cyclosporine nephropathy: The Achilles' heel of immunosuppressive therapy. Kidney Int 1996;50:1089-100,

6. De Mattos AM, Olyaei AJ, Bennett WM. Nephrotoxicity of immunosuppressive drugs: Long-term consequences and challenges for the future. Am J Kidney Dis 2000;35:333-46.

7. Olyaei AJ, de Mattos AM, Bennett WM. Nephrotoxicity of immunosuppressive drugs: New insight and preventive strategies. Curr Opin Crit Care 2001;7:384-9.

8. Myers BD, Newton L, Boshkos C, et al. Chronic injury of human renal microvessels with low-dose cyclosporine therapy. Transplantation 1988;46:694-703.

9. Dieterle A, Gratwohl A, Nizze H, et al. Chronic cyclosporineassociated nephrotoxicity in bone marrow transplant patients. Transplantation 1990;49:1093-100.

10. Zaltzman JS, Pei Y, Maurer J, Patterson A, Cattran DC. Cyclosporine nephrotoxicity in lung transplant recipients. Transplantation 1992;54:875-8.

11. Goldstein DJ, Zuech N, Sehgal V, Weinberg AD, Drusin R, Cohen D. Cyclosporine-associated end-stage nephropathy after cardiac transplantation: Incidence and progression. Transplantation 1997;63:664-8. 
12. Andres A, Morales JM, Farias J, et al. Acute renal failure after liver transplantation in patients treated with cyclosporine. Transplant Proc 1992;24:126-7.

13. Pascual E, Gomez-Arnau J, Pensado A, et al. Incidence and risk factors of early acute renal failure in liver transplant patients. Transplant Proc 1993;25:1837.

14. Gonwa TA, Mai ML, Melton LB, et al. End-stage renal disease (ESRD) after orthotopic liver transplantation (OLTX) using calcineurin-based immunotherapy: Risk of development and treatment. Transplantation 2001;72:1934-9.

15. Decruyenaere J, Colardyn F, Mortier E, et al. Early postoperative renal dysfunction after adult liver transplantation. Transplant Proc 1995;27:3497-9.

16. Padbury RT, Toogood GJ, McMaster P. Withdrawal of immunosuppression in liver allograft recipients. Liver Transpl Surg $1998 ; 4: 242-8$

17. Mazariegos GV, Reyes J, Marino IR, et al. Weaning of immunosuppression in liver transplant recipients. Transplantation $1997 ; 63: 243-9$

18. Goddard S, Adams DH. New approaches to immunosuppression in liver transplantation. J Gastroenterol Hepatol 2002;17:116-26.

19. Distant DA, Gonwa TA. The kidney in liver transplantation. J Am Soc Nephrol 1993;4:129-36.

20. Axelsen RA, Crawford DH, Endre ZH, et al. Renal glomerular lesions in unselected patients with cirrhosis undergoing orthotopic liver transplantation. Pathology 1995;27:237-46.

21. Lhotta K. Beyond hepatorenal syndrome: Glomerulonephritis in patients with liver disease. Semin Nephrol 2002;22:302-8.

22. Crawford DH, Endre ZH, Axelsen RA, et al. Universal occurrence of glomerular abnormalities in patients receiving liver transplants. Am J Kidney Dis 1992;19:339-44.

23. Davis CL, Gretch DR, Perkins JD, et al. Hepatitis C-associated glomerular disease in liver transplant recipients. Liver Transpl Surg 1995;1:166-75.

24. Kendrick EA, McVicar JP, Kowdley KV, et al. Renal disease in hepatitis C-positive liver transplant recipients. Transplantation 1997;63:1287-93

25. Abrahamian GA, Cosimi AB, Farrell ML, Schoenfeld DA, Chung RT, Pascual M. Prevalence of hepatitis $C$ virus-associated mixed cryoglobulinemia after liver transplantation. Liver Transpl 2000;6:185-90.

26. Cantarell MC, Charco R, Capdevila L, et al. Outcome of hepatitis $\mathrm{C}$ virus-associated membranoproliferative glomerulonephritis after liver transplantation. Transplantation 1999;68:1131-4.

27. Brown RS Jr, Lombardero M, Lake JR. Outcome of patients with renal insufficiency undergoing liver or liver-kidney transplantation. Transplantation 1996;62:1788-93.

28. Lafayette RA, Pare G, Schmid CH, King AJ, Rohrer RJ, Nasraway SA. Pretransplant renal dysfunction predicts poorer outcome in liver transplantation. Clin Nephrol 1997;48:159-64.

29. Dagher L, Moore K. The hepatorenal syndrome. Gut 2001;49:729-37.

30. Arroyo V, Gines P, Jimenez V, et al. Renal dysfunction in cirrhosis. In: Bircher J, Benhamou J-P, McIntyre N, et al, eds. Oxford Textbook of Clinical Hepatology. Oxford: Oxford University Press, 1999:733-61.

31. Gonwa TA, Morris CA, Goldstein RM, Husberg BS, Klintmalm GB. Long-term survival and renal function following liver transplantation in patients with and without hepatorenal syndrome - experience in 300 patients. Transplantation 1991;51:428-30.

32. Gonwa TA, Klintmalm GB, Levy M, Jennings LS, Goldstein RM, Husberg BS. Impact of pretransplant renal function on survival after liver transplantation. Transplantation 1995;59:361-5.

33. Winkler M, Brinkmann C, Jost U, Oldhafer K, Ringe B, Pichlmayr R. Long-term side effects of cyclosporine-based immunosuppression in patients after liver transplantation. Transplant Proc 1994:26:2679-82.

34. Semhoun-Ducloux S, Ducloux D, Bresson-Hadni S, et al. Systemic hypertension and renal function in long-term liver transplant recipients on cyclosporine. Transplant Proc 2000;32:449-52.

35. Tomlanovich S, Golbetz H, Perlroth M, Stinson E, Myers BD. Limitations of creatinine in quantifying the severity of cyclosporineinduced chronic nephropathy. Am J Kidney Dis 1986;8:332-7.

36. Papadakis MA, Arieff AI. Unpredictability of clinical evaluation of renal function in cirrhosis. Prospective study. Am J Med 1987;82:945-52.
37. Walser M, Drew HH, LaFrance ND. Creatinine measurements often yielded false estimates of progression in chronic renal failure. Kidney Int 1988;34:412-8.

38. Cohen AJ, Stegall MD, Rosen CB, et al. Chronic renal dysfunction late after liver transplantation. Liver Transpl 2002;8:916-21.

39. Lynn M, Abreo K, Zibari G, McDonald J. End-stage renal disease in liver transplants. Clin Transplant 2001;15(Suppl 6):66-9.

40. McDiarmid SV, Colonna JO 2nd, Shaked A, Ament ME, Busuttil RW. A comparison of renal function in cyclosporine- and FK-506-treated patients after primary orthotopic liver transplantation. Transplantation 1993;56:847-53.

41. European FK506 Multicentre Liver Study Group. Randomised trial comparing tacrolimus (FK506) and cyclosporin in prevention of liver allograft rejection. Lancet 1994;344:423-8.

42. The US Multicenter FK506 Liver Study Group. A comparison of tacrolimus (FK 506) and cyclosporine for immunosuppression in liver transplantation. N Engl J Med 1994;331:1110-5.

43. Mor E, Patel T, Glabman S, et al. Comparison of short and longterm renal function in liver transplant patients receiving cyclosporin or FK 506. Transpl Int 1994;7(Suppl 1):S77-80.

44. Wiesner RH. A long-term comparison of tacrolimus (FK506) versus cyclosporine in liver transplantation: A report of the United States FK506 Study Group. Transplantation 1998;66:493-9.

45. Falkenhain ME, Cosio FG, Sedmak DD. Progressive histologic injury in kidneys from heart and liver transplant recipients receiving cyclosporine. Transplantation 1996;62:364-70.

46. Andoh TF, Bennett WM. Chronic cyclosporine nephrotoxicity. Curr Opin Nephrol Hypertens 1998;7:265-70.

47. Lyson T, Ermel LD, Belshaw PJ, Alberg DG, Schreiber SL, Victor RG. Cyclosporine- and FK506-induced sympathetic activation correlates with calcineurin-mediated inhibition of T-cell signaling. Circ Res 1993;73:596-602.

48. Sander M, Lyson T, Thomas GD, Victor RG. Sympathetic neural mechanisms of cyclosporine-induced hypertension. Am J Hypertens 1996;9:121S-38S.

49. Murray BM, Paller MS, Ferris TF. Effect of cyclosporine administration on renal hemodynamics in conscious rats. Kidney Int 1985;28:767-74.

50. Coffman TM, Carr DR, Yarger WE, Klotman PE. Evidence that renal prostaglandin and thromboxane production is stimulated in chronic cyclosporine nephrotoxicity. Transplantation 1987;43:282-5.

51. Prevot A, Semama DS, Justrabo E, Guignard JP, Escousse A, Gouyon JB. Acute cyclosporine A-induced nephrotoxicity: A rabbit model. Pediatr Nephrol 2000;14:370-5.

52. Weir MR, Klassen DK, Shen SY, Sullivan D, Buddemeyer EU, Handwerger BS. Acute effects of intravenous cyclosporine on blood pressure, renal hemodynamics, and urine prostaglandin production of healthy humans. Transplantation 1990;49:41-7.

53. Petric R, Freeman D, Wallace C, McDonald J, Stiller C, Keown P. Effect of cyclosporine on urinary prostanoid excretion, renal blood flow, and glomerulotubular function. Transplantation 1988;45:883-9.

54. Lanese DM, Conger JD. Effects of endothelin receptor antagonist on cyclosporine-induced vasoconstriction in isolated rat renal arterioles. J Clin Invest 1993;91:2144-9.

55. Ramirez C, Olmo A, O'Valle F, et al. Role of intrarenal endothelin 1, endothelin 3, and angiotensin II expression in chronic cyclosporin A nephrotoxicity in rats. Exp Nephrol 2000;8:161-72.

56. Andoh TF, Gardner MP, Bennett WM. Protective effects of dietary L-arginine supplementation on chronic cyclosporine nephrotoxicity. Transplantation 1997;64:1236-40.

57. Shihab FS, Yi H, Bennett WM, Andoh TF. Effect of nitric oxide modulation on TGF-betal and matrix proteins in chronic cyclosporine nephrotoxicity. Kidney Int 2000;58:1174-85.

58. Amore A, Emancipator SN, Cirina P, et al. Nitric oxide mediates cyclosporine-induced apoptosis in cultured renal cells. Kidney Int 2000;57:1549-59.

59. Yamamoto T, Noble NA, Miller DE, Border WA. Sustained expression of TGF-beta 1 underlies development of progressive kidney fibrosis. Kidney Int 1994;45:916-27.

60. Pankewycz OG, Miao L, Isaacs R, et al. Increased renal tubular expression of transforming growth factor beta in human allografts correlates with cyclosporine toxicity. Kidney Int 1996;50:1634-40.

61. Shin GT, Khanna A, Ding R, et al. In vivo expression of transforming growth factor-betal in humans: Stimulation by cyclosporine. Transplantation 1998;65:313-8. 
62. Cuhaci B, Kumar MS, Bloom RD, et al. Transforming growth factorbeta levels in human allograft chronic fibrosis correlate with rate of decline in renal function. Transplantation 1999;68:785-90.

63. Khanna AK, Cairns VR, Becker CG, Hosenpud JD. Transforming growth factor (TGF)-beta mimics and anti-TGF-beta antibody abrogates the in vivo effects of cyclosporine: Demonstration of a direct role of TGF-beta in immunosuppression and nephrotoxicity of cyclosporine. Transplantation 1999;67:882-9.

64. Ader JL, Rostaing L. Cyclosporin nephrotoxicity: Pathophysiology and comparison with FK-506. Curr Opin Nephrol Hypertens 1998;7:539-45.

65. Khanna A, Cairns V, Hosenpud JD. Tacrolimus induces increased expression of transforming growth factor-betal in mammalian lymphoid as well as nonlymphoid cells. Transplantation 1999;67:614-9

66. Schorn TF, Kliem V, Bojanovski M, et al. Impact of long-term immunosuppression with cyclosporin A on serum lipids in stable renal transplant recipients. Transpl Int 1991;4:92-5.

67. Kasiske BL, Tortorice KL, Heim-Duthoy KL, Awni WM, Rao KV. The adverse impact of cyclosporine on serum lipids in renal transplant recipients. Am J Kidney Dis 1991;17:700-7.

68. Manzarbeitia C, Reich DJ, Rothstein KD, Braitman LE, Levin S, Munoz SJ. Tacrolimus conversion improves hyperlipidemic states in stable liver transplant recipients. Liver Transpl 2001;7:93-9.

69. Ligtenberg G, Hene RJ, Blankestijn PJ, Koomans HA. Cardiovascular risk factors in renal transplant patients: Cyclosporin A versus tacrolimus. J Am Soc Nephrol 2001;12:368-73.

70. Atillasoy E, Gurkan A, Mor E, et al. Cholesterol levels long-term after liver transplant. Transplant Proc 1998;30:2049-50.

71. Wellman KF, Volk BW. Renal changes in experimental hypercholesterolemia in normal and subdiabetic rabbits. II. Long term studies. Lab Invest 1971;24:144-55.

72. Moorhead JF, Chan MK, El-Nahas M, Varghese Z. Lipid nephrotoxicity in chronic progressive glomerular and tubulointerstitial disease. Lancet 1982;ii:1309-11.

73. Kasiske BL, O'Donnell MP, Garvis WJ, Keane WF. Pharmacologic treatment of hyperlipidemia reduces glomerular injury in rat 5/6 nephrectomy model of chronic renal failure. Circ Res 1988;62:367-74.

74. Kasiske BL, O'Donnell MP, Cleary MP, Keane WF. Treatment of hyperlipidemia reduces glomerular injury in obese Zucker rats. Kidney Int 1988;33:667-72.

75. Harris KP, Purkerson ML, Yates J, Klahr S. Lovastatin ameliorates the development of glomerulosclerosis and uremia in experimental nephrotic syndrome. Am J Kidney Dis 1990;15:16-23.

76. Kasiske BL, O’Donnell MP, Schmitz PG, Kim Y, Keane WF. Renal injury of diet-induced hypercholesterolemia in rats. Kidney Int 1990;37:880-91.

77. Fried LF, Orchard TJ, Kasiske BL. Effect of lipid reduction on the progression of renal disease: A meta-analysis. Kidney Int 2001;59:260-9

78. Coonrod BA, Ellis D, Becker DJ, et al. Predictors of microalbuminuria in individuals with IDDM. Pittsburgh Epidemiology of Diabetes Complications Study. Diabetes Care 1993; 16:1376-83.

79. Krolewski AS, Warram JH, Christlieb AR. Hypercholesterolemia a determinant of renal function loss and deaths in IDDM patients with nephropathy. Kidney Int Suppl 1994;45:S125-31.

80. Stegall MD, Wachs ME, Everson G, et al. Prednisone withdrawal 14 days after liver transplantation with mycophenolate: A prospective trial of cyclosporine and tacrolimus. Transplantation 1997;64:1755-60.

81. Bostom AD, Brown RS Jr, Chavers BM, et al. Prevention of posttransplant cardiovascular disease - report and recommendations of an ad hoc group. Am J Transplant 2002;2:491-500.

82. Kahan BD. Efficacy of sirolimus compared with azathioprine for reduction of acute renal allograft rejection: A randomised multicentre study. The Rapamune US Study Group. Lancet 2000;356:194-202.

83. MacDonald AS. RAPAMUNE Global Study Group. A worldwide, phase III, randomized, controlled, safety and efficacy study of a sirolimus/cyclosporine regimen for prevention of acute rejection in recipients of primary mismatched renal allografts. Transplantation 2001;71:271-80.

84. Neuhaus P, Klupp J, Langrehr JM. mTOR inhibitors: An overview. Liver Transpl 2001;7:473-84.
85. Porreca E, Di Febbo C, Mincione G, et al. Increased transforming growth factor-beta production and gene expression by peripheral blood monocytes of hypertensive patients. Hypertension 1997;30:134-9.

86. Rabkin JM, Corless CL, Rosen HR, Olyaei AJ. Immunosuppression impact on long-term cardiovascular complications after liver transplantation. Am J Surg 2002;183:595-9.

87. Canzanello VJ, Schwartz L, Taler SJ, et al. Evolution of cardiovascular risk after liver transplantation: A comparison of cyclosporine A and tacrolimus (FK506). Liver Transpl Surg 1997;3:1-9.

88. Textor SC, Taler SJ, Canzanello VJ, Schwartz L, Augustine JE. Posttransplantation hypertension related to calcineurin inhibitors. Liver Transpl 2000;6:521-30.

89. Weir MR, Fink JC. Risk for posttransplant diabetes mellitus with current immunosuppressive medications. Am J Kidney Dis 1999;34:1-13.

90. Border WA, Noble NA. Transforming growth factor beta in tissue fibrosis. N Engl J Med 1994;331:1286-92.

91. Iwano M, Kubo A, Nishino T, et al. Quantification of glomerular TGF-beta 1 mRNA in patients with diabetes mellitus. Kidney Int 1996;49:1120-6

92. Neuhaus P, Blumhardt G, Bechstein WO, et al. Comparison of FK506- and cyclosporine-based immunosuppression in primary orthotopic liver transplantation. A single center experience. Transplantation 1995;59:31-40.

93. Stegall MD, Everson GT, Schroter G, et al. Prednisone withdrawal late after adult liver transplantation reduces diabetes, hypertension, and hypercholesterolemia without causing graft loss. Hepatology 1997;25:173-7.

94. Davis CL, Gonwa TA, Wilkinson AH. Identification of patients best suited for combined liver-kidney transplantation: Part II. Liver Transpl 2002;8:193-211.

95. Cantarovich M, Giannetti N, Cecere R. Correlation between serum creatinine, creatinine clearance, the calculated creatinine clearance and the glomerular filtration rate in heart transplant patients. J Heart Lung Transplant 2002;21:815-7.

96. Cantarovich M, Giannetti N, Cecere R. Cimetidine improves the assessment of the glomerular filtration rate in heart transplant recipients. Am J Transplant 2003;3(Suppl 5):384.

97. McClellan W. As to diseases, make a habit of two things - to help, or at least do no harm. J Am Soc Nephrol 2002;13:2817-9.

98. Clase CM, Garg AX, Kiberd BA. Prevalence of low glomerular filtration rate in nondiabetic Americans: Third National Health and Nutrition Examination Survey (NHANES III). J Am Soc Nephrol 2002;13:1338-49.

99. Newman DJ, Thakkar H, Edwards RG, et al. Serum cystatin C measured by automated immunoassay: A more sensitive marker of changes in GFR than serum creatinine. Kidney Int 1995;47:312-8.

100. Mussap M, Dalla Vestra M, Fioretto P, et al. Cystatin C is a more sensitive marker than creatinine for the estimation of GFR in type 2 diabetic patients. Kidney Int 2002;61:1453-61.

101. Mussap M, Ruzzante N, Varagnolo M, Plebani M. Quantitative automated particle-enhanced immunonephelometric assay for the routine measurement of human cystatin C. Clin Chem Lab Med 1998;36:859-65.

102. Taylor JE, Calne RY, Stewart WK. Massive cystic hepatomegaly in a female patient with polycystic kidney disease treated by combined hepatic and renal transplantation. Q J Med 1991;80:771-5.

103. Jeyarajah DR, Gonwa TA, Testa G, et al. Liver and kidney transplantation for polycystic disease. Transplantation 1998;66:529-32.

104. Chui AK, Koorey D, Pathania OP, Rao AR, McCaughan GW, Sheil AG. Polycystic disease: A rare indication for combined liver and kidney transplantation. Hong Kong Med J 2000;6:116-8.

105. Shaked A, Thompson M, Wilkinson AH, et al. The role of combined liver/kidney transplantation in end-stage hepato-renal disease. Am Surg 1993;59:606-9.

106. Ghabra N, Piraino B, Greenberg A, Banner B. Resolution of cirrhotic glomerulonephritis following successful liver transplantation. Clin Nephrol 1991;35:6-9.

107. Quan A, Portale A, Foster S, Lavine J. Resolution of hepatitis B virus-related membranoproliferative glomerulonephritis after orthotopic liver transplantation. Pediatr Nephrol 1995;9:599-602.

108. Hoch B, Juknevicius I, Liapis H. Glomerular injury associated with hepatitis $\mathrm{C}$ infection: A correlation with blood and tissue HCV-PCR. Semin Diagn Pathol 2002;19:175-87. 
109. Lui SL, Halloran PF. Mycophenolate mofetil in kidney transplantation. Curr Opin Nephrol Hypertens 1996;5:508-13.

110. Allison AC, Almquist SJ, Muller CD, Eugui EM. In vitro immunosuppressive effects of mycophenolic acid and an ester pro-drug, RS-61443. Transplant Proc 1991;23(Suppl 2):10-4.

111. Gummert JF, Barten MJ, Sherwood SW, van Gelder T, Morris RE. Pharmacodynamics of immunosuppression by mycophenolic acid: Inhibition of both lymphocyte proliferation and activation correlates with pharmacokinetics. J Pharmacol Exp Ther 1999;291:1100-12.

112. Blaheta RA, Leckel K, Wittig B, et al. Inhibition of endothelial receptor expression and of T-cell ligand activity by mycophenolate mofetil. Transpl Immunol 1998;6:251-9.

113. Romero F, Rodriguez-Iturbe B, Parra G, Gonzalez L, Herrera-Acosta J, Tapia E. Mycophenolate mofetil prevents the progressive renal failure induced by $5 / 6$ renal ablation in rats. Kidney Int 1999;55:945-55.

114. Allison AC, Eugui EM. Preferential suppression of lymphocyte proliferation by mycophenolic acid and predicted long-term effects of mycophenolate mofetil in transplantation. Transplant Proc 1994:26:3205-10.

115. Zeier M, Deppisch R, Dikow R, Schwenger V, Wiesel M. Inhibition of fibroblast growth by mycophenolic acid is mediated by apoptosis. Am J Transplant 2002;2(Suppl 3):321. (Abst)

116. Sollinger HW. Mycophenolate mofetil for the prevention of acute rejection in primary cadaveric renal allograft recipients. US Renal Transplant Mycophenolate Mofetil Study Group. Transplantation 1995;60:225-32.

117. European Mycophenolate Mofetil Cooperative Study Group. Placebo-controlled study of mycophenolate mofetil combined with cyclosporin and corticosteroids for prevention of acute rejection. Lancet 1995;345:1321-5.

118. The Tricontinental Mycophenolate Mofetil Renal Transplantation Study Group. A blinded, randomized clinical trial of mycophenolate mofetil for the prevention of acute rejection in cadaveric renal transplantation. Transplantation 1996;61:1029-37.

119. Halloran P, Mathew T, Tomlanovich S, Groth C, Hooftman L, Barker C. Mycophenolate mofetil in renal allograft recipients: A pooled efficacy analysis of three randomized, double-blind, clinical studies in prevention of rejection. The International Mycophenolate Mofetil Renal Transplant Study Groups. Transplantation 1997;63:39-47.

120. Kobashigawa J, Miller L, Renlund D, et al. A randomized activecontrolled trial of mycophenolate mofetil in heart transplant recipients. Mycophenolate Mofetil Investigators. Transplantation 1998;66:507-15.

121. Wiesner R, Rabkin J, Klintmalm G, et al. A randomized doubleblind comparative study of mycophenolate mofetil and azathioprine in combination with cyclosporine and corticosteroids in primary liver transplant recipients. Liver Transpl 2001;7:442-50.

122. Levy GA, Grant D, Paradis K, Campestrini J, Smith T, Kovarik JM. Pharmacokinetics and tolerability of 40-0-[2-hydroxyethyl] rapamycin in de novo liver transplant recipients. Transplantation 2001;71:160-3.

123. Valantine H, Eisen H, Dorent R, et al. 12-Month results of a multicenter study comparing efficacy and safety of everolimus to azathioprine in de novo cardiac transplant recipients. Am J Transplant 2002;2(Suppl 3):247. (Abst)

124. Rapamune Oral Solution (sirolimus) Prescribing Information. Murray L, Kelly GI, eds. Physicians' Desk Reference. Montvale: Medical Economics Company Inc, 2002:3584-9.

125. Trotter JF. Sirolimus in liver transplantation. Transplant Proc 2003;35(3 Suppl):193S-200S.

126. Neff GW, Montalbano M, Tzakis AG. Ten years of sirolimus therapy in orthotopic liver transplant recipients. Transplant Proc 2003;35(Suppl 3):209S-16S.

127. Watson CJ, Friend PJ, Jamieson NV, et al. Sirolimus: A potent new immunosuppressant for liver transplantation. Transplantation 1999;67:505-9.

128. Pridohl O, Heinemann K, Hartwig T, et al. Low-dose immunosuppression with FK 506 and sirolimus after liver transplantation: 1-year results. Transplant Proc 2001;33:3229-31.

129. McAlister VC, Peltekian KM, Malatjalian DA, et al. Orthotopic liver transplantation using low-dose tacrolimus and sirolimus. Liver Transpl 2001;7:701-8.
130. Wyeth Pharmaceuticals. Rapamune. Important correction of drug information (Lett). <http://www.fda.gov/medwatch/SAFETY/2002/ Rapamune_Deardoc.pdf> (Version current at July 19, 2004).

131. Cantarovich M, Barkun J, Metrakos P, et al. Anti-thymocyte globulin allows delayed introduction of calcineurin inhibitors with a low rejection rate in liver transplant patients with post-operative acute renal failure requiring dialysis. Am J Transplant 2002;2(Suppl 3):198. (Abst)

132. Emre S, Gondolesi G, Polat K, et al. Use of daclizumab as initial immunosuppression in liver transplant recipients with impaired renal function. Liver Transpl 2001;7:220-5.

133. Hirose R, Roberts JP, Quan D, et al. Experience with daclizumab in liver transplantation: Renal transplant dosing without calcineurin inhibitors is insufficient to prevent acute rejection in liver transplantation. Transplantation 2000;69:307-11.

134. Cantarovich M, Besner JG, Barkun JS, Elstein E, Loertscher R. Two-hour cyclosporine level determination is the appropriate tool to monitor Neoral therapy. Clin Transplant 1998;12:243-9.

135. Cantarovich M, Barkun JS, Tchervenkov JI, Besner JG, Aspeslet L, Metrakos P. Comparison of Neoral dose monitoring with cyclosporine through levels versus 2 -hr postdose levels in stable liver transplant patients. Transplantation 1998;66:1621-7.

136. Levy G, Burra P, Cavallari A, et al. Improved clinical outcomes for liver transplant recipients using cyclosporine monitoring based on 2-hr post-dose levels (C2). Transplantation 2002;73:953-9.

137. Levy G, Thervet E, Lake J, Uchida K. Consensus on Neoral C(2): Expert Review in Transplantation (CONCERT) Group. Patient management by Neoral C(2) monitoring: An international consensus statement. Transplantation 2002;73(9 Suppl):S12-8.

138. Armstrong VW, Oellerich M. New developments in the immunosuppressive drug monitoring of cyclosporine, tacrolimus, and azathioprine. Clin Biochem 2001;34:9-16.

139. Kershner RP, Fitzsimmons WE. Relationship of FK506 whole blood concentrations and efficacy and toxicity after liver and kidney transplantation. Transplantation 1996;62:920-6.

140. Ringe B, Braun F, Lorf T, et al. Tacrolimus and mycophenolate mofetil in clinical liver transplantation: Experience with a steroidsparing concept. Transplant Proc 1998;30:1415-6.

141. Hedayat S, Kershner RP, Su G. Relationship of whole-blood FK506 concentrations to rejection and toxicity in liver and kidney transplants. J Biopharm Stat 1996;6:411-24.

142. Laskow DA, Vincenti F, Neylan JF, Mendez R, Matas AJ. An open-label, concentration-ranging trial of FK506 in primary kidney transplantation: A report of the United States Multicenter FK506 Kidney Transplant Group. Transplantation 1996;62:900-5.

143. Cantarovich M, Fridell J, Barkun J, et al. Optimal time points for the prediction of the area-under-the-curve in liver transplant patients receiving tacrolimus. Transplant Proc 1998;30:1460-1.

144. Sandborn WJ, Hay JE, Porayko MK, et al. Cyclosporine withdrawal for nephrotoxicity in liver transplant recipients does not result in sustained improvement in kidney function and causes cellular and ductopenic rejection. Hepatology 1994;19:925-32.

145. Papatheodoridis GV, O’Beirne J, Mistry P, Davidson B, Rolles K, Burroughs AK. Mycophenolate mofetil monotherapy in stable liver transplant patients with cyclosporine-induced renal impairment: A preliminary report. Transplantation 1999;68:155-7.

146. Herrero JI, Quiroga J, Sangro B, et al. Conversion of liver transplant recipients on cyclosporine with renal impairment to mycophenolate mofetil. Liver Transpl Surg 1999;5:414-20.

147. Schlitt HJ, Barkmann A, Boker KH, et al. Replacement of calcineurin inhibitors with mycophenolate mofetil in livertransplant patients with renal dysfunction: A randomised controlled study. Lancet 2001;357:587-91.

148. Nair S, Eason J, Loss G. Sirolimus monotherapy in nephrotoxicity due to calcineurin inhibitors in liver transplant recipients. Liver Transpl 2003;9:126-9.

149. Fairbanks KD, Eustace JA, Fine D, Thuluvath PJ. Renal function improves in liver transplant recipients when switched from a calcineurin inhibitor to sirolimus. Liver Transpl 2003;9:1079-85.

150. Jain A, Kashyap R, Dodson F, et al. A prospective randomized trial of tacrolimus and prednisone versus tacrolimus, prednisone and mycophenolate mofetil in primary adult liver transplantation: A single center report. Transplantation 2001;72:1091-7.

151. Chang GJ, Mahanty HD, Quan D, et al. Experience with the use of sirolimus in liver transplantation - use in patients for whom 
calcineurin inhibitors are contraindicated. Liver Transpl 2000;6:734-40.

152. Nagahara Y, Ikekita M, Shinomiya T. Immunosuppressant FTY720 induces apoptosis by direct induction of permeability transition and release of cytochrome c from mitochondria. J Immunol 2000;165:3250-9.

153. Li XK, Tamura A, Fujino M, et al. Induction of lymphocyte apoptosis in rat liver allograft with ongoing rejection by FTY720. Clin Exp Immunol 2001;123:331-9.

154. Pinschewer DD, Ochsenbein AF, Odermatt B, Brinkmann V, Hengartner H, Zinkernagel RM. FTY720 immunosuppression impairs effector $\mathrm{T}$ cell peripheral homing without affecting induction, expansion, and memory. J Immunol 2000;164:5761-70.

155. Wang ME, Tejpal N, Qu X, et al. Immunosuppressive effects of FTY720 alone or in combination with cyclosporine and/or sirolimus. Transplantation 1998;65:899-905.

156. Tamura A, Li XK, Funeshima N, et al. Immunosuppressive therapy using FTY720 combined with tacrolimus in rat liver transplantation. Surgery 2000;127:47-54.

157. Furukawa H, Suzuki T, Jin MB, et al. Prolongation of canine liver allograft survival by a novel immunosuppressant, FTY720: Effect of monotherapy and combined treatment with conventional drugs. Transplantation 2000;69:235-41.

158. Cantarovich M, Tzimas GN, Barkun J, Deschûnes M, Alpert E, Tchervenkov J. Efficacy of mycophenolate mofetil combined with very low-dose cyclosporine microemulsion in long-term liver transplant patients with renal dysfunction. Transplantation 2003;76:98-102.

159. Kreis H, Cisterne JM, Land W, et al. Sirolimus in association with mycophenolate mofetil induction for the prevention of acute graft rejection in renal allograft recipients. Transplantation 2000;69:1252-60.

160. Johnson RW, Kreis H, Oberbauer R, Brattstrom C, Claesson K, Eris J. Sirolimus allows early cyclosporine withdrawal in renal transplantation resulting in improved renal function and lower blood pressure. Transplantation 2001;72:777-86.

161. Eckhoff DE, McGuire BM, Frenette LR, Contreras JL, Hudson SL, Bynon JS. Tacrolimus (FK506) and mycophenolate mofetil combination therapy versus tacrolimus in adult liver transplantation. Transplantation 1998;65:180-7.
162. Trotter JF, Wachs ME, Trouillot TE, et al. Dyslipidemia during sirolimus therapy in liver transplant recipients occurs with concomitant cyclosporine but not tacrolimus. Liver Transpl 2001;7:401-8.

163. Cantarovich M, Metrakos P, Giannetti N, Cecere J, Barkun J, Tchervenkov J. Ani-CD25 monoclonal antibody coverage allows for calcineurin inhibitor "holiday" in solid organ transplant patients with acute renal dysfunction. Transplantation 2002;73:1169-72.

164. Broekroelofs J, Stegeman CA, Navis G, Tegzess AM, de Zeeuw D, de Jong PE. Risk factors for long-term renal survival after renal transplantation: A role for angiotensin-converting enzyme (insertion/deletion) polymorphism? J Am Soc Nephrol 1998;9:2075-81.

165. Viklicky O, Hubacek JA, Pitha J, et al. ACE gene polymorphism and long-term renal graft function. Clin Biochem 2001;34:87-90.

166. Abdi R, Tran TB, Zee R, Brenner BM, Milford EL. Angiotensin gene polymorphism as a determinant of posttransplantation renal dysfunction and hypertension. Transplantation 2001;72:726-9.

167. Nicod J, Richard A, Frey FJ, Ferrari P. Recipient RAS gene variants and renal allograft function. Transplantation 2002;73:960-5.

168. Noble NA, Border WA. Angiotensin II in renal fibrosis: Should TGF-beta rather than blood pressure be the therapeutic target? Semin Nephrol 1997;17:455-66.

169. Mervaala E, Lassila M, Vaskonen T, et al. Effects of ACE inhibition on cyclosporine A-induced hypertension and nephrotoxicity in spontaneously hypertensive rats on a high-sodium diet. Blood Press 1999;8:49-56.

170. Shin GT, Kim SJ, Ma KA, Kim HS, Kim D. ACE inhibitors attenuate expression of renal transforming growth factor-beta1 in humans. Am J Kidney Dis 2000;36:894-902.

171. Remuzzi A, Gagliardini E, Donadoni C, et al. Effect of angiotensin II antagonism on the regression of kidney disease in the rat. Kidney Int 2002;62:885-94.

172. Langham RG, Egan MK, Dowling JP, Gilbert RE, Thomson NM. Transforming growth factor-betal and tumor growth-factor-betainducible gene- $\mathrm{H} 3$ in nonrenal transplant cyclosporine nephropathy. Transplantation 2001;72:1826-9. 


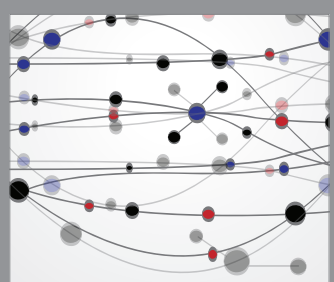

The Scientific World Journal
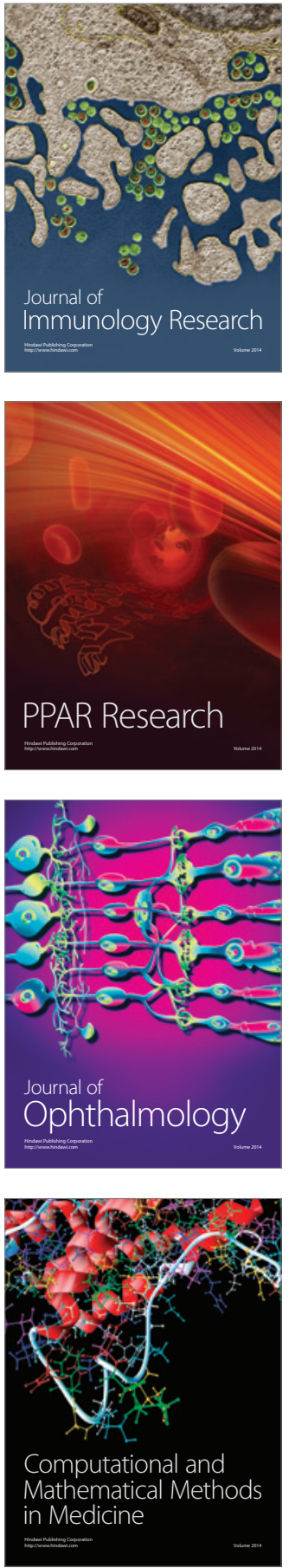

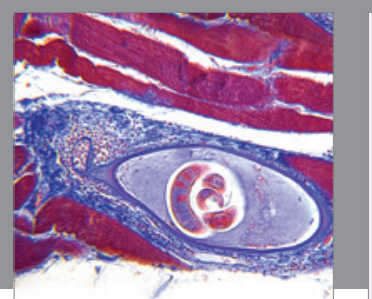

Gastroenterology Research and Practice

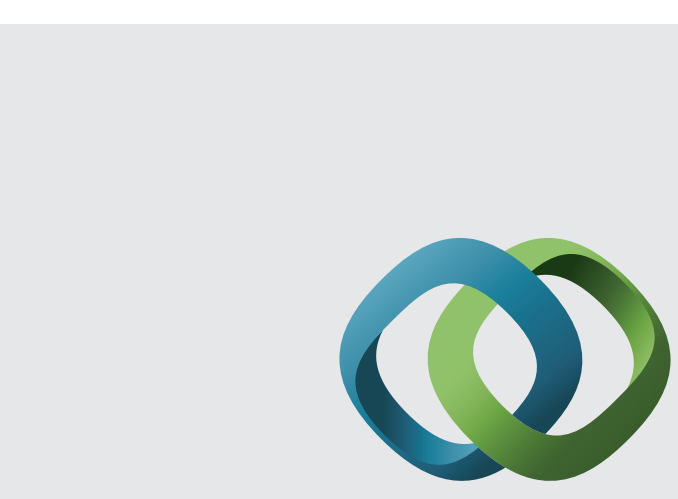

\section{Hindawi}

Submit your manuscripts at

http://www.hindawi.com
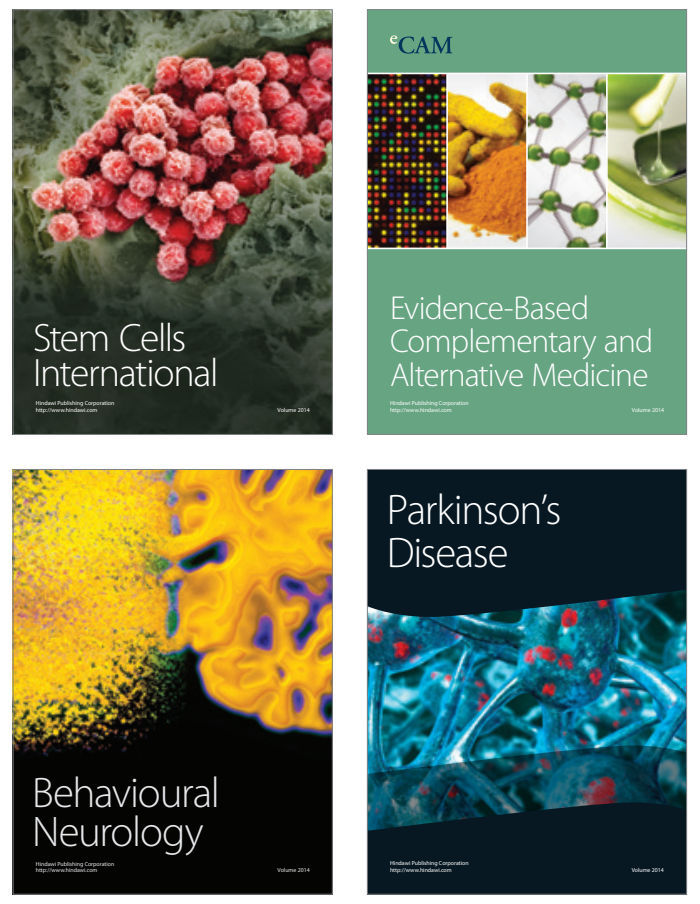
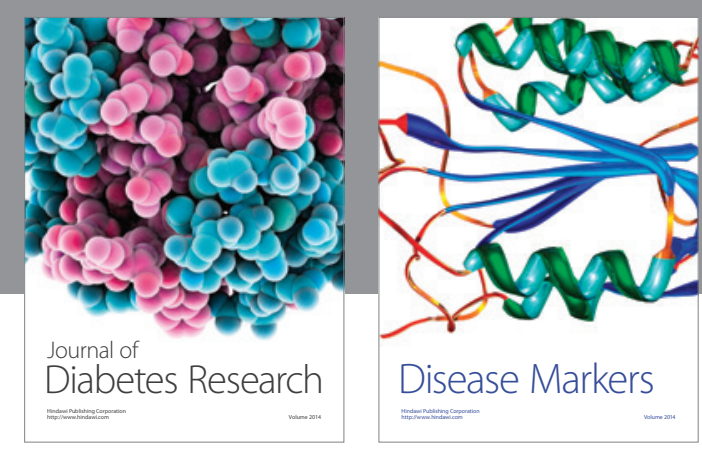

Disease Markers
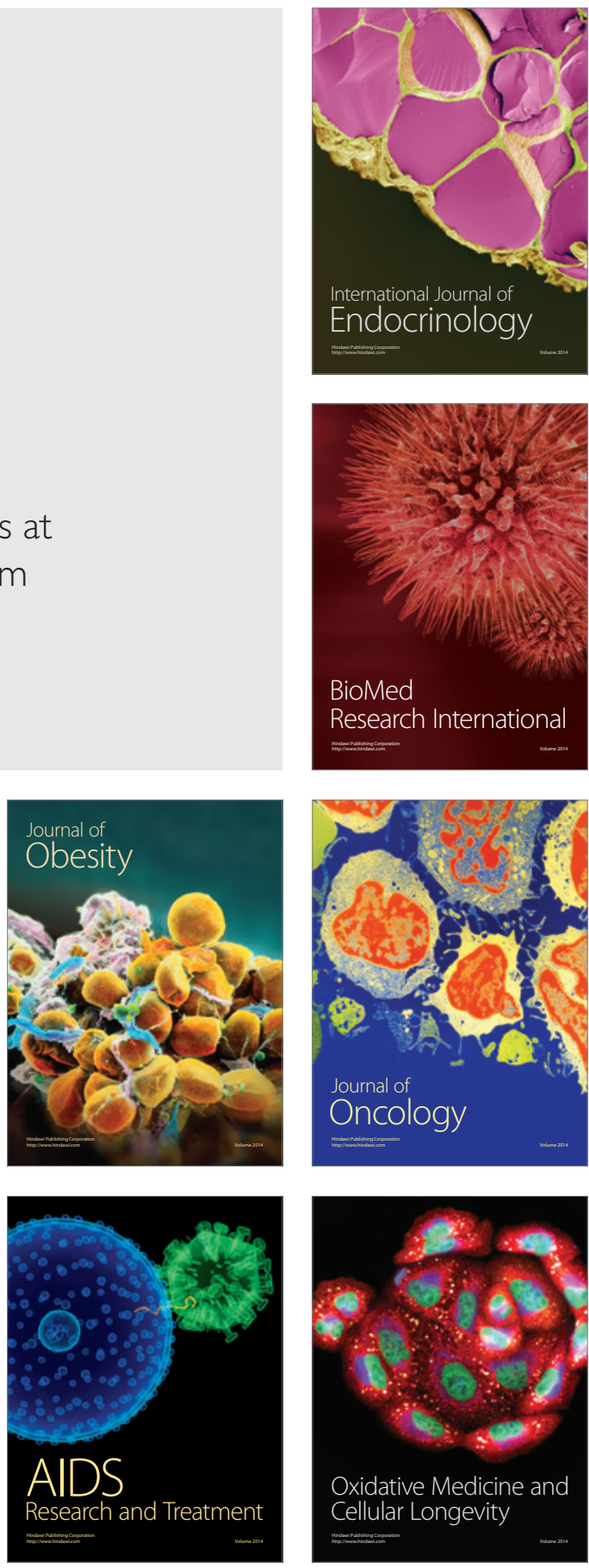